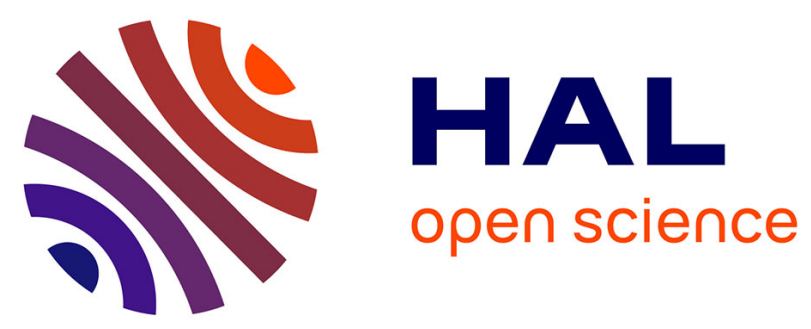

\title{
Hydrothermal transformation of titanate scrolled nanosheets to anatase over a wide ph range and contribution of triethanolamine and oleic acid to control the morphology
}

Qingguo Bai, Magali Lavenas, Laetitia Vauriot, Quentin Le Trequesser, Junjie Hao, François Weill, Jean-Pierre Delville, Marie-Hélène Delville

\section{To cite this version:}

Qingguo Bai, Magali Lavenas, Laetitia Vauriot, Quentin Le Trequesser, Junjie Hao, et al.. Hydrothermal transformation of titanate scrolled nanosheets to anatase over a wide ph range and contribution of triethanolamine and oleic acid to control the morphology. Inorganic Chemistry, 2019, 58 (4), pp.2588-2598. 10.1021/acs.inorgchem.8b03197 . hal-02051494

\author{
HAL Id: hal-02051494 \\ https://hal.science/hal-02051494
}

Submitted on 27 Feb 2019

HAL is a multi-disciplinary open access archive for the deposit and dissemination of scientific research documents, whether they are published or not. The documents may come from teaching and research institutions in France or abroad, or from public or private research centers.
L'archive ouverte pluridisciplinaire HAL, est destinée au dépôt et à la diffusion de documents scientifiques de niveau recherche, publiés ou non, émanant des établissements d'enseignement et de recherche français ou étrangers, des laboratoires publics ou privés.

\section{(1)(1) $\$(0)$}

Distributed under a Creative Commons Attribution - NonCommercial - ShareAlikel 4.0 


\title{
Hydrothermal Transformation of Titanate Scrolled
}

\author{
Nanosheets to Anatase over a Wide pH Range and
}

Contribution of Triethanolamine and Oleic Acid to

\section{Control the Morphology}

Bai Q. ${ }^{a, b}$, Lavenas M. ${ }^{a}$, Vauriot L. ${ }^{a, b}$ Le Tréquesser Q. ${ }^{a}$, Hao J. ${ }^{a, b}$, Weill F. ${ }^{a}$, Delville J.P. ${ }^{b}$, Delville M.H. ${ }^{a}{ }^{*}$

${ }^{\text {a }}$ CNRS, Univ. Bordeaux, ICMCB, UMR 5026, 33608 Pessac, France

${ }^{\mathrm{b}}$ Univ. Bordeaux, LOMA, CNRS, UMR 5798, 33405 Talence, France

KEYWORDS: Anatase, hydrothermal synthesis, morphology control structuring agents. 


\section{ABSTRACT}

Mild hydrothermal conditions used for the treatment of titanate scrolled nanosheets (SNSs) suspensions $\left(140^{\circ} \mathrm{C}, 72 \mathrm{~h}\right)$ resulted in a large variety of anatase $\mathrm{TiO}_{2}$ anisotropic nanoobjects depending on the studied parameters: influence of the medium $\mathrm{pH}$, the presence or not of structuring agents. The present work shows that such a hydrothermal treatment of the SNSs, whatever the $\mathrm{pH}$, resulted in the formation of single-crystalline anatase nanoneedles (NNs) with a specific crystal-elongation direction and a $\mathrm{pH}$-dependent morphological anisotropy with aspect ratios from 1 to 8 . The SNSs suspensions were prepared by the conventional ultra-basic treatment of $\mathrm{TiO}_{2}$ with $\mathrm{NaOH}$, followed by washing with $\mathrm{HNO}_{3}$ to different $\mathrm{pH}$ values. The crystal size of the anatase $\mathrm{TiO}_{2}$ obtained from this hydrothermal treatment increased with the $\mathrm{pH}$ of the suspensions, from $15 \mathrm{~nm}$ nanoparticles (NPs) (aspect ratio $\mathrm{AR}=1$ ) at $\mathrm{pH} 2.2$ to 500 nm NNs $(\mathrm{AR}=8)$ at a pH 10.8 with a long axis systematically along the anatase [001] direction. Triethanol amine (TEOA) and Oleic acid (OA) were used as structuring agents (SAs). Their respective influence when acting on their own, had little influence on the control of the size, shape or polydispersity of the NNs. However, their concomitant use provided a much better control of not only the size and polydispersity which was strongly reduced, but also on (i) the shape and morphology giving rise to a controlled access to well-defined nanorods as opposed to nanoneedles (ii) the crystal phase purity eliminating the few $\%$ brookite still visible in the XRD patterns of samples prepared in SA free conditions. This approach offers an on-demand control over the production of anatase morphologies with defined aspect ratios. 


\section{INTRODUCTION}

Nanosized titanium dioxide has attracted much attention, over the past decades, due to exceptional optical and electronic properties, ${ }^{1}$ high efficiency and high photo-stability, strong oxidizing power, ${ }^{2}$ chemical stability $^{3-4}$ leading to many applications ${ }^{5}$ in catalysis, photocatalysis, ${ }^{6-7}$ solar cells, ${ }^{8-9}$ (bio)sensing ${ }^{10-11}$ and biomedicine. ${ }^{12}$ The photo-activity of $\mathrm{TiO}_{2},{ }^{13-14}$ is influenced not only by different properties such as the surface area, the crystallinity, the nanoparticle (NP) size or the crystal structure, ${ }^{14-15}$ but also by the specific morphology of the particles, which determines which crystal facets are exposed, and then has a strong influence on the photocatalytic performance of the particles. ${ }^{16}$ Both theoretical and experimental studies have shown that the (001) surface of the $\mathrm{TiO}_{2}$ anatase truncated bipyramid which exhibits $100 \%$ of Ti five-fold coordinated (Ti5c) is much more reactive than the thermodynamically more stable (101) facet presenting 50\% of Ti5c and 50\% of Ti six-fold coordinated Ti6c. ${ }^{17-22}$ On the other hand, when NPs are expected to be very reactive, one cannot ignore their impact and their potential toxicity. ${ }^{23-32}$ The latter depends not only on the chemical nature of the nanomaterial, but also on its size, morphology and surface chemistry. ${ }^{12,25,30,33-43}$ Therefore, for toxicology and other purposes, the synthesis of well-crystallized and nanostructured $\mathrm{TiO}_{2}$ particles with tailored morphology is still the object of intense research and represents a current major challenge using either no capping agent, inorganic $\left(\mathrm{F}^{-}\right)$or organic capping agents (amines, long chain organic acids). ${ }^{5,21,44-49}$ These agents that specifically adsorb on different facets can play a critical role in assisting the anisotropic growth of specific facets so that the NP develops in targeted directions and controlled morphology. Besides the numerous molecular titanium precursors $^{41,50}$ (alkoxides, halides, titanium bis(ammoniumlactato) hydroxide, sulfate and oxysulfate, atranes, carboxylates) to grow $\mathrm{TiO}_{2} \mathrm{NPs}$, the use of the so-called titania-based nanotubes was successfully tested by Nian et al. in $2006 .{ }^{51}$ The synthesis of these titania-based nanotubes (TNTs), also referred to as scrolled nanosheets (SNSs), is based on the hydrothermal 
treatment of $\mathrm{TiO}_{2}$ powder, at high temperatures in a highly concentrated $\mathrm{NaOH}$ solution without sacrificial templates and was first reported by Kasuga et al. ${ }^{52-53}$ in 1998 . This simple and costeffective hydrothermal method provides a large scale quantity of pure titania-based nanotubes with small diameter $(9-10 \mathrm{~nm})$ and lengths as high as several hundred $\mathrm{nms}$ and has been the subject of many efforts. ${ }^{33,37,54}$ The different studies on the reactivity of these SNSs in various media $^{19,33,55-64}$ show they can be effectively used as a cost-effective starting material as compared to titanium alkoxides for the controlled synthesis of targeted morphologies of $\mathrm{TiO}_{2}$. We propose in this paper to use these SNSs in hydrothermal conditions under mild conditions $\left(140^{\circ} \mathrm{C}, 3\right.$ days $)$ and scan the influence of parameters such the $\mathrm{pH}$ and the nature of the capping agents suggested by Sugimoto to direct NPs growth starting from molecular precursors. ${ }^{65} \mathrm{We}$ show that over a wide $\mathrm{pH}$ range (2.2-11) it is possible to control the morphology of the anatase $\mathrm{TiO}_{2}$ from nanocuboids to high aspect ratio nanoneedles (NNs) as illustrated in Scheme 1.

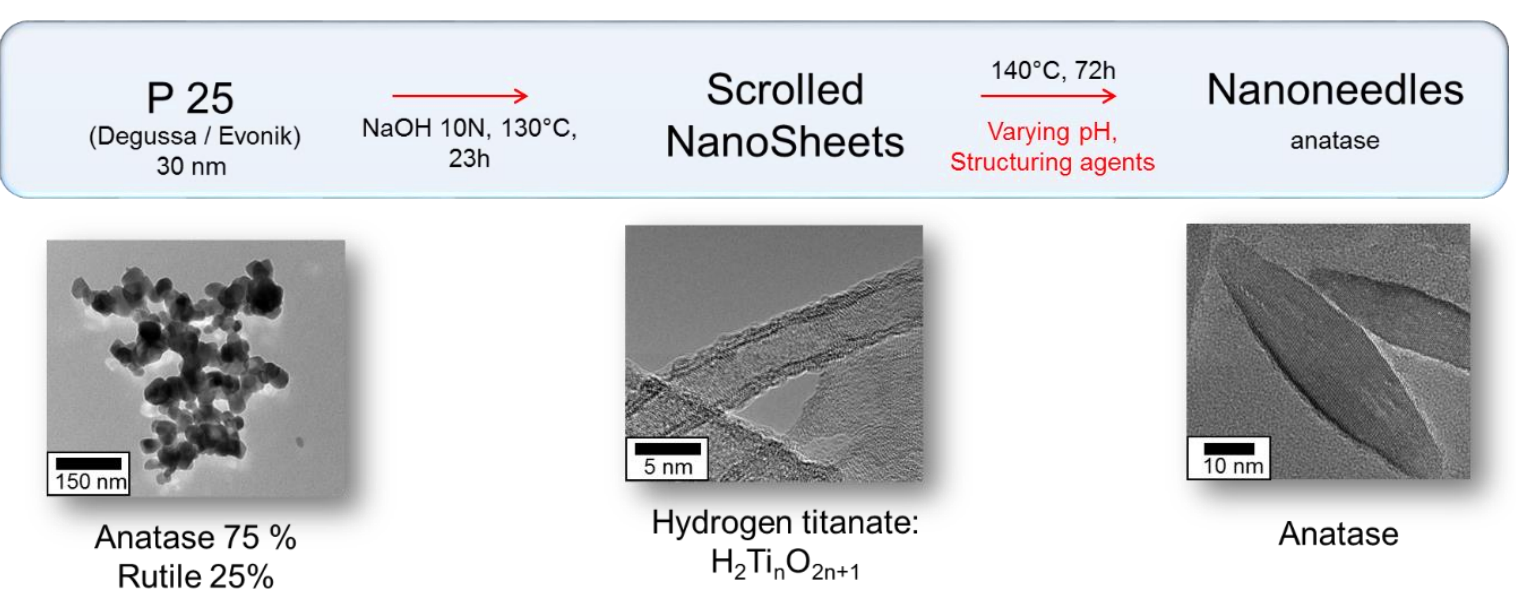

Scheme 1. Illustration of the reaction procedure to control the NNs aspect ratios: in red the parameters are varied in this study.

These nanoobjects with controlled morphology can then provide a panel for further use in biological studies to find correlations in between cells discrepancy and the aspect ratio of the NNs. 


\section{EXPERIMENTAL SECTION}

Synthesis of SNSs: The scrolled nanosheets were synthesized by a traditional hydrothermal route based on the initial work by Kasuga and co-workers. ${ }^{52-53}$ The synthetic procedure for $\mathrm{TiO}_{2}$ based scrolled nanosheets was as follows: P25 from Evonik ( $2 \mathrm{~g}, 25 \mathrm{mmol})$ a generous gift from Evonik was introduced into a Teflon vessel with an inner volume of $50 \mathrm{~mL}$ and added with a freshly prepared under Argon $10 \mathrm{~N} \mathrm{NaOH}$ aqueous solution $(30 \mathrm{~mL}$ (prepared in a Teflon Erlenmeyer), 0.3 mol.) (caution should be taken to avoid carbonation of sodium hydroxide solution). The Teflon vessel was sealed and placed on a roller mixer for 1 hour; it was then introduced inside a stainless steel autoclave and subjected to a hydrothermal treatment at $130^{\circ} \mathrm{C}$ for 23 hours. The autogenous pressure is not an issue because the saturation pressure of $10 \mathrm{~N}$ $\mathrm{NaOH}$ is ca. 1.2 bar at this temperature, thus it varies very little between 100 and $150^{\circ} \mathrm{C}$, and can be easily controlled by strictly controlling the filling fraction of the PTFE container. ${ }^{66}$ The mixture was then naturally cooled down, the transparent supernatant removed. The white solid was collected, and washed with $150 \mathrm{~mL}$ of $0.1 \mathrm{~N} \mathrm{HNO}_{3}$ solution for 15 minutes and submitted to centrifugation steps of 5,000 rpm for 10 minutes. This process was repeated until $\mathrm{pH}$ became acidic (an overall volume of $600 \mathrm{~mL}$ was necessary). Finally, the colloidal solution was neutralized with deionized water to get a stable $\mathrm{pH}$ of 7 . The same procedure was used for the treatment with $1 \mathrm{~N} \mathrm{HNO}_{3}$ and $0.1 \mathrm{~N}$ and $1 \mathrm{~N} \mathrm{HCl}$.

Synthesis of Nanoneedles: The synthesis of nanoneedles using the previously prepared scrolled nanosheets is adapted from Nian's. ${ }^{51}$ A $1 \mathrm{~N} \mathrm{NaOH}$ solution was added dropwise to one-third of the freshly prepared scrolled nanosheet suspension corresponding to $0.7 \mathrm{~g}$ of powder, in order to reach the required $\mathrm{pH}$ (measured with a $\mathrm{pH}$-meter), and to adjust the volume to $28 \mathrm{~mL}$. It was then added to a $50 \mathrm{~mL}$ Teflon vessel in a stainless steel autoclave which was placed in an oven at $140{ }^{\circ} \mathrm{C}$ for 72 hours after which the mixture was naturally cooled down and washed with deionized water until pH 7 (centrifugation steps: 9,000 rpm, 10 minutes). The addition of 
the structuring agents, (triethanolamine (TEOA), oleic acid (OA)), to freshly synthesized scrolled nanosheets was performed before adjusting the $\mathrm{pH}$.

Then, the $\mathrm{pH}$ was adjusted to the desired value and the volume to $28 \mathrm{~mL}$ with $\mathrm{NaOH}$ or $\mathrm{HNO}_{3}$ solutions and distilled water. Finally, the mixture was introduced to a Teflon-lined stainless steel autoclave and subjected to hydrothermal treatment at $140^{\circ} \mathrm{C}$ for 72 hours. The two other thirds were also used as starting materials, as soon as prepared. The overall yield of such a process starting from $2 \mathrm{~g}$ of $\mathrm{TiO}_{2}$ based on the two reactions in Scheme 1 and taking into account the many washing steps per batch was in the range $85-87 \%$.

The samples were heated in a programmable Memmert oven. The phase identification of the samples was performed with X-Ray Diffraction (XRD) using a powder diffractometer (PANalytical X'Pert Pro) equipped with CuKa1 radiation, $\lambda=1.540598 \AA$. Transmission Electron Microscopy (TEM) images were obtained with either a TEM 1400 JEOL using 120 $\mathrm{kV}$ voltage or on an Hitachi H7650 operating at $120 \mathrm{kV}$. HRTEM images were obtained with a TEM-FEG HR (JEOL 2200FS) at $200 \mathrm{kV}$.

\section{RESULTS AND DISCUSSION}

The alkaline-based hydrothermal synthesis developed by Kasuga et al. has rapidly turned out to be the dominant non-templated method for producing scrolled nanosheets ${ }^{52}$ and/or layered titanate nanomaterials. ${ }^{67}$ The main advantages of the procedure as mentioned in the introduction is that it relies on the use of cheap raw materials $\left(\mathrm{TiO}_{2}\right.$ whatever its nature: anatase, commercial $\mathrm{P} 25,{ }^{52,67-68}$ rutile, ${ }^{53,68-69}$ or amorphous $\mathrm{TiO}_{2}{ }^{70}, \mathrm{NaOH}$ or $\mathrm{KOH}^{67}$, water), exhibits high yields of single phase nanomaterial as well as the possibility to control the product morphology by tuning the composition of the reaction mixture. In a typical SNSs synthesis, anatase $\mathrm{TiO}_{2}$ is mixed into a $10 \mathrm{M} \mathrm{NaOH}$ aqueous solution until a white suspension is obtained, the suspension is then 
aged in a closed Teflon-lined autoclave at a determined temperature for a given time without shaking or stirring except in one case. ${ }^{71}$ The product is then washed with either deionized water or acidic solutions at various concentrations, to reach a chosen $\mathrm{pH}$ at which point the slurry is filtered, and the titanate nanotubes are dried in air or kept in solution depending on their further use.

The result of these different treatments is that the number of papers, which were published on the structure and formation of hydrothermally synthesized titanium oxide nanotubes/scrolled nanosheets, led to controversial reports especially concerning their crystalline structure. ${ }^{33,72-73}$ We therefore here were cautious to always use exactly the same experimental conditions, in terms of concentration of P25, use of freshly prepared sodium hydroxide solution (under argon), reaction time and temperature, as well as the washing procedure to ensure a constant reproducibility of the SNSs. The accurate control of this procedure was indeed mandatory to better understand the influence of the different studied parameters when these SNSs were used as starting materials for further syntheses. As shown in Figure 1, each SNS consists of a thin curved structure of several layers of a single nanosheet wrapped on itself, along with the c axis, leading to a nanotube with an average external diameter of about $8 \mathrm{~nm}$ with a multiwall thickness of about $2 \mathrm{~nm}$ and a length of several hundred nanometers. ${ }^{74}$ The interlayer spacing of these nanotubes is $0.7 \mathrm{~nm}$, close to the values reported in the literature. ${ }^{55,70,75-77}$

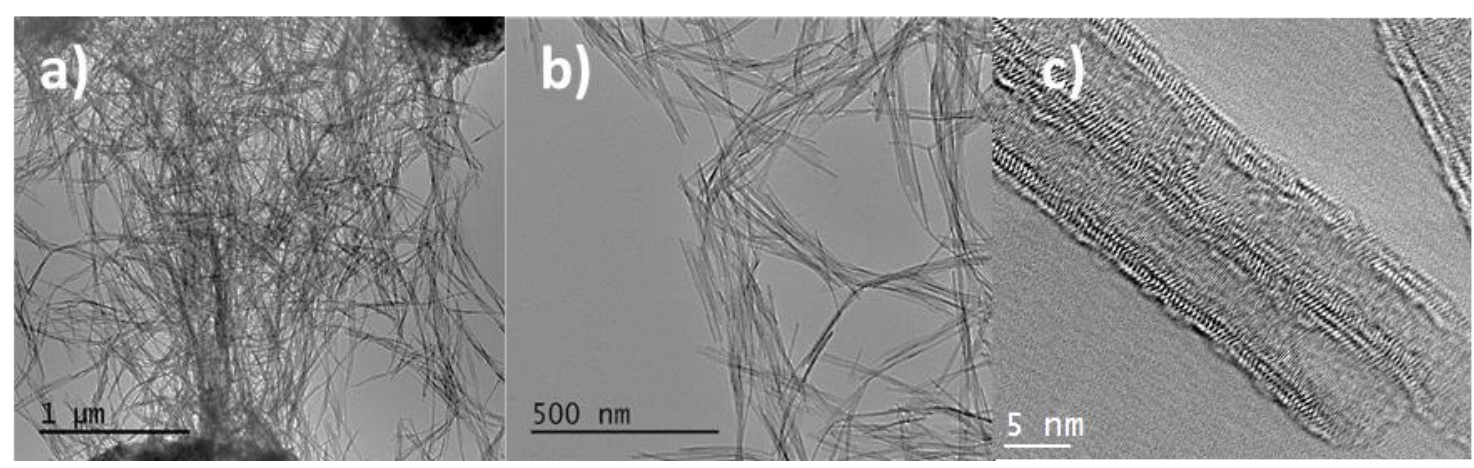

Figure 1. a) and b) TEM images of scrolled nanosheets at two magnifications after the acid 
washing at $0.1 \mathrm{~N} \mathrm{HNO}_{3}$; c) HRTEM of the same SNSs showing the scrolled nature of the objects.

The XRD patterns (Figure 2) of these scrolled nanosheets were analyzed at the different steps of the washing process: with doubly distilled water, $\mathrm{HCl}(0.1 \mathrm{~N}$ and $1 \mathrm{~N})$ and $\mathrm{HNO}_{3}(0.1 \mathrm{~N}$ and $1 \mathrm{~N}$ ) solutions respectively and a subsequent drying at $40{ }^{\circ} \mathrm{C}$ for one night.

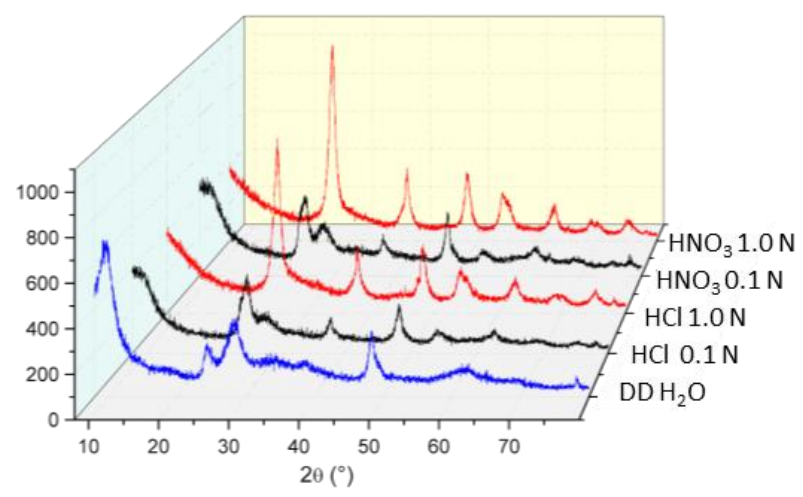

Figure 2. XRD Patterns of scrolled nanosheets after various washing procedures showing the importance of the $\mathrm{pH}$ on the resulting structure.

The first observation concerns the absence of an influence of the chemical nature of the acid, only the acid concentration plays a crucial role. Comparing the effects of neutral and acidic washings on the XRD patterns shows the major expected diffraction peaks at $2 \theta=9.3^{\circ}, 24.4^{\circ}$, $28.5^{\circ}$ and $48.3^{\circ}$ characteristic of the tubular $\mathrm{Ti}_{3} \mathrm{O}_{7}^{2-}$ layer resulting from the $\mathrm{NaOH}$ treatment of $\mathrm{TiO}_{2}$ nanopowder, shifts to $2 \theta=8.7,25.2^{\circ}, 27.9^{\circ}$ and $48.6^{\circ}$ for $0.1 \mathrm{~N} \mathrm{HNO}_{3}$ while a peak appears at $38^{\circ}$ as well as an inversion of 2 peaks intensities in the $25-28^{\circ}$ range with a complete disappearance of the latter after $1 \mathrm{~N}$ acid washing. This evolution of the diffraction patterns matches the structural modification with the acid treatment: while $\mathrm{Na}^{+}$ions are replaced by the bigger $\mathrm{H}_{3} \mathrm{O}^{+}$between the sheets during the washing process $\left(\mathrm{Na}_{2} \mathrm{Ti}_{3} \mathrm{O}_{7} \rightarrow \mathrm{Na}_{x} \mathrm{H}_{2-\mathrm{x}} \mathrm{Ti}_{3} \mathrm{O}_{7}\right) .{ }^{52,78-}$ ${ }^{80}$ Many explanations have been given in the literature for the same type of XRD patterns. Authors claimed that in the $\mathrm{Ti}_{3} \mathrm{O}_{7}{ }^{2-}$ layer they obtained, three edge-shared $\mathrm{TiO}_{6}$ octahedra joined 
at the corner to form the stepped $\mathrm{Ti}_{3} \mathrm{O}_{7}{ }^{2-}$ layers; sodium ions and water molecules located between the layers were exchangeable and assumed a general formula of $\mathrm{Na}_{\mathrm{x}} \mathrm{H}_{2-\mathrm{x}} \mathrm{Ti}_{3} \mathrm{O}_{7}$ depending on the washing. ${ }^{61,81}$ However, such XRD patterns were also attributed to $\mathrm{H}_{2} \mathrm{Ti}_{2} \mathrm{O}_{5} \cdot \mathrm{H}_{2} \mathrm{O}^{51,69,82-86}$ or orthorhombic protonic lepidocrocite $\left(\mathrm{H}_{\mathrm{x}} \mathrm{Ti}_{2-\mathrm{x} / 4 \square_{\mathrm{x}} / 4} \mathrm{O}_{4}\right.$ with $\mathrm{x} \sim 0.7$ and $\square$ : vacancy). ${ }^{20}$ This is why the obtained product is very often considered to be a protonated form of titanium oxide or hydrogeno titanate, formulated under pressure. ${ }^{33}$

In the following, we took special care to use the same washing procedure, like equal volumes of $0.1 \mathrm{~N} \mathrm{HNO}_{3}$ and the same periods of time, to be sure to obtain identical SNSs. The SNSs then underwent a hydrothermal treatment at $140^{\circ} \mathrm{C}$ with an identical autoclave filling fraction of $60 \%$ in all the experiments, during which we varied different parameters: the reaction time, the aging of the precursor SNSs, the $\mathrm{pH}$ of the reaction medium as well as the presence of structuring agents such as TEOA and/or OA. The SNSs were transformed into $\mathrm{TiO}_{2} \mathrm{NNs}_{\text {with }}$ various lengths and aspect ratios depending on the studied parameters. As an example, when a suspension of $0.7 \mathrm{~g}$ of scrolled nanosheets underwent reaction at $140{ }^{\circ} \mathrm{C}$ for 72 hours at $\mathrm{pH} 9.8$ treatment, nanoneedles as shown in Figure 3 a) are obtained. The XRD analysis (Figure 3b) shows the characteristic peaks of the well-crystallized anatase structure (JCPDS 21-1272) are dominant with a few \% of brookite (JCPDS 029-1360) barely detectable. ${ }^{45}$

The statistical distribution of their lengths and widths measured on at least 300 NPs (Figures 3 c) and d)) provided an average length of $350 \mathrm{~nm}( \pm 130 \mathrm{~nm})$, and width of $46 \mathrm{~nm}( \pm 10 \mathrm{~nm})$ and aspect ratio (AR) of 7.5 . 

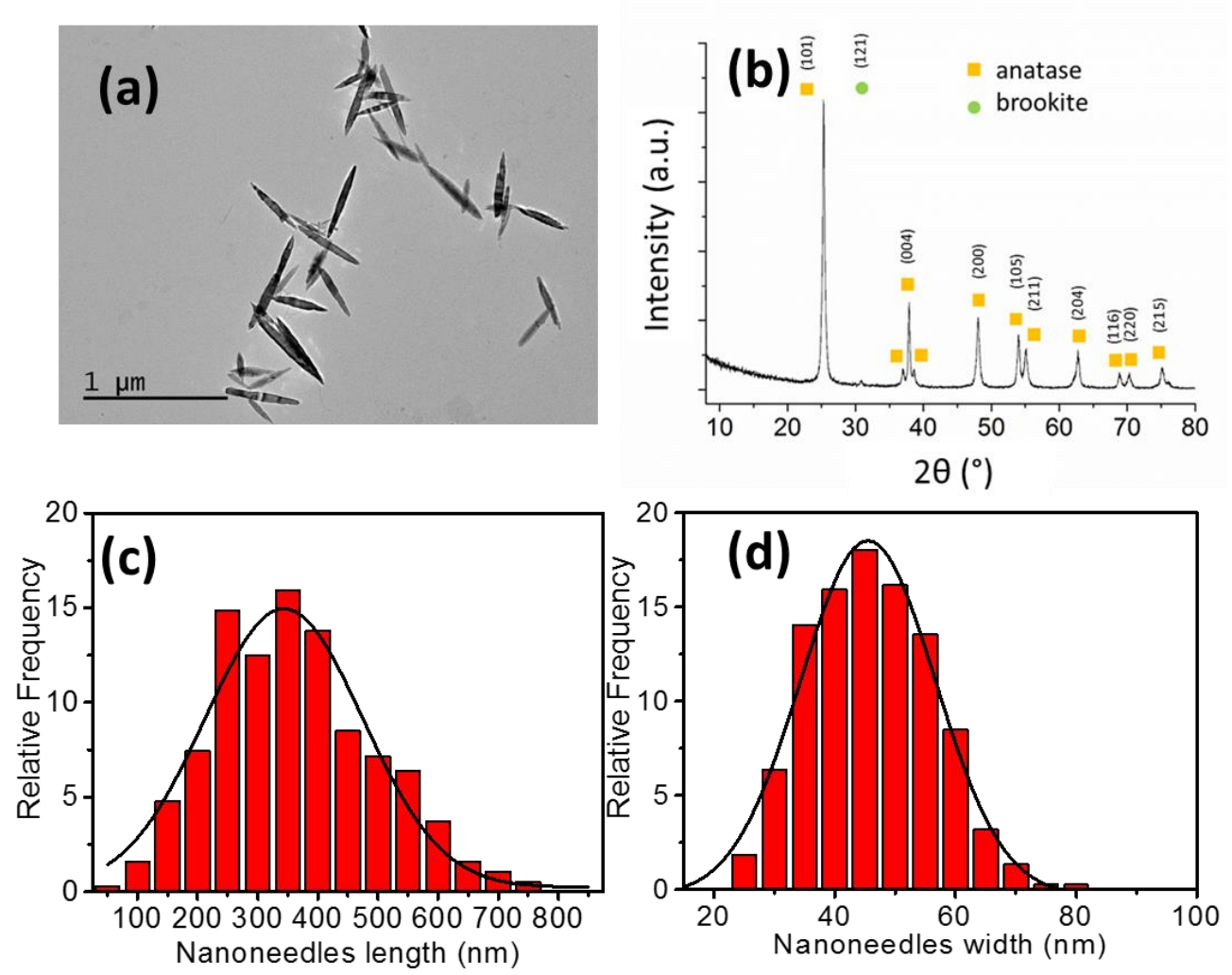

Figure 3. (a) TEM image and (b) XRD pattern of $\mathrm{TiO}_{2}$ nanoneedles (c) and (d) statistical distribution of nanoneedles length and width respectively. $\left(140{ }^{\circ} \mathrm{C}\right.$ for 72 hours at $\left.\mathrm{pH} 9.8\right)$.

Influence of the reaction time: In most of the papers, the required operating time used for the transformation of the SNSs into other $\mathrm{TiO}_{2}$ morphologies at $140^{\circ} \mathrm{C}$ is generally 3 days, we effectively confirmed that $24 \mathrm{~h}$ and $48 \mathrm{~h}$ reaction times respectively have a $\%$ conversion of only $50 \%$ and $80 \%$ of the SNSs at $140{ }^{\circ} \mathrm{C}$.

Influence of the SNS aging. The parameters of a $\mathrm{pH}$ of 9.8 and a hydrothermal treatment at 140 ${ }^{\circ} \mathrm{C}$ for 3 days, were fixed to study the influence of the SNSs aging. Figure 4 compares the freshly-prepared SNSs (Figure 4a) and the morphology (Figure 4b) and size distribution (Figure 4c) of the resulting $\mathrm{TiO}_{2} \mathrm{NNs}$ and the same SNSs stored in water solution at $\mathrm{pH} 7$ for 31 days at room temperature (Figure $4 \mathrm{~d}$ ) and their resulting $\mathrm{TiO}_{2} \mathrm{NNs}$ (Figure $4 \mathrm{e}$ and Figure $4 \mathrm{f}$ ). At such a $\mathrm{pH}$, no phase transformation of the SNSs into more stable nanoobjects was detected ${ }^{55}$, they tend to shorten as well as un-scroll leading to smaller nanoobjects when submitted to 
hydrothermal treatment. Their XRD pattern is also detrimentally influenced by a long storage in neutral water as shown in Figure 5a.
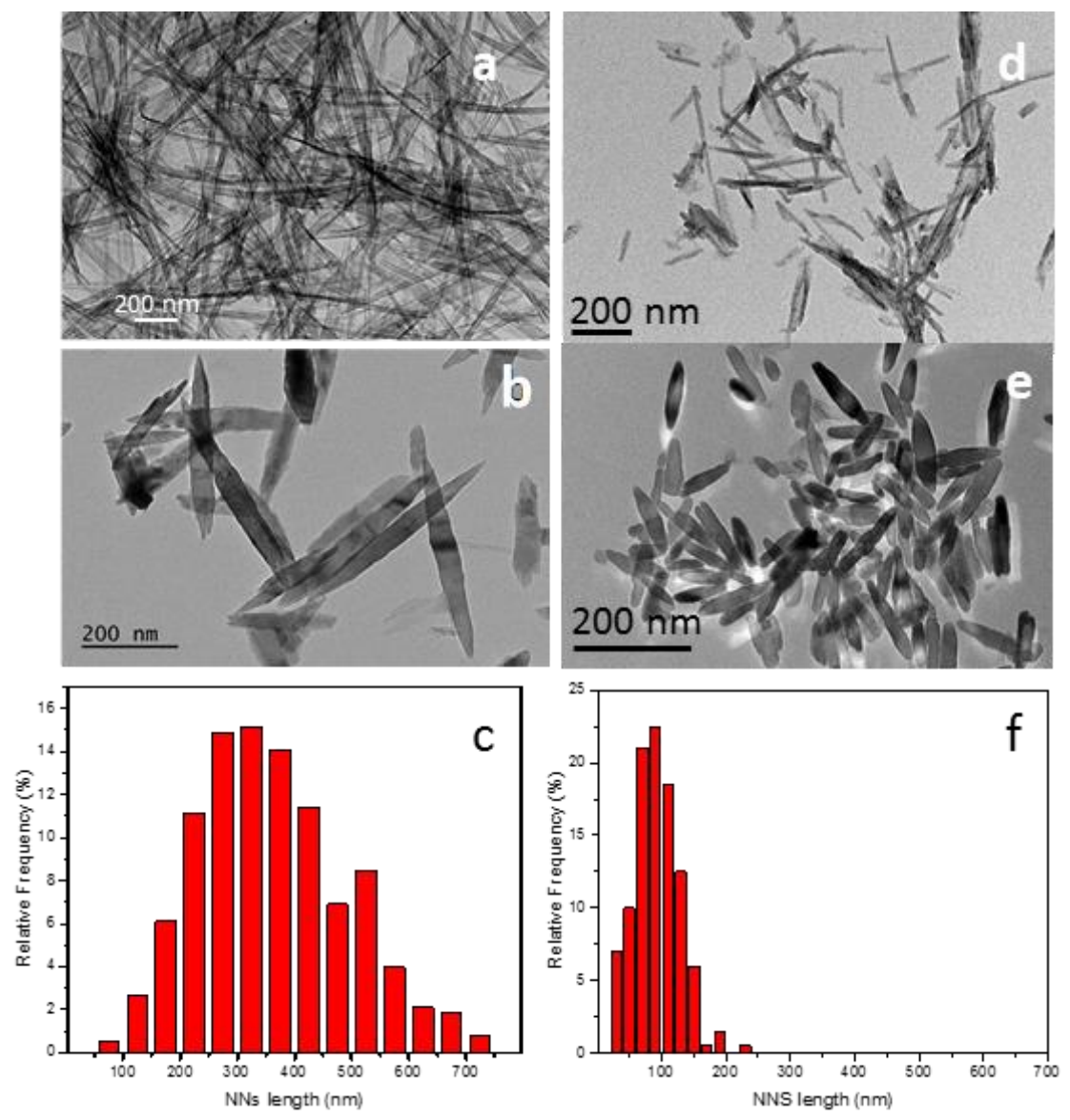

Figure 4. (a and d) TEM images of fresh and 1-month old SNSs respectively; TEM images (b and, e) and length distribution (c and f) of NNs obtained from fresh and 1-month old SNSs respectively ( $\mathrm{pH} 9.8$, hydrothermal treatment at $140{ }^{\circ} \mathrm{C}$ for 3 days).

Figures $4 \mathrm{~b}$ and $4 \mathrm{e}$ are the TEM images of their corresponding NNs with the size distribution made on the length of more than 300 particles (Figures 4c and 4f). NNs obtained from freshlymade SNSs exhibit an average length of $350 \mathrm{~nm}( \pm 140 \mathrm{~nm})$ whereas SNSs obtained from "old" SNSs are much smaller with an average length of $92 \mathrm{~nm}( \pm 30 \mathrm{~nm})$. The same trend is observed with the NNs width. A more systematic study of the aging of the nanosheets from 0 to 31 days was performed to determine the impact on the nanoneedles length as shown in Figure 5b. 

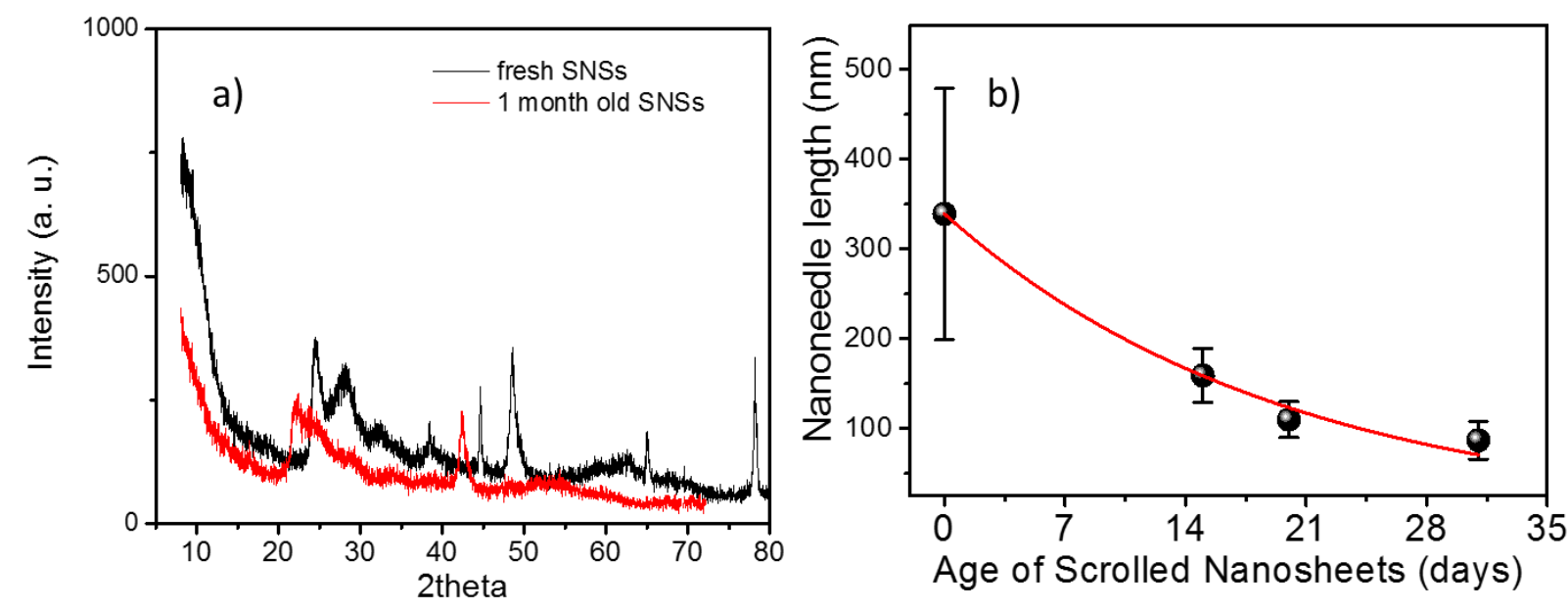

Figure 5. a) Variation of the XRD pattern of the SNSs with time; b) variation of NNs length as a function of the age of SNSs ( $\mathrm{pH} 9.8$, hydrothermal treatment at $140{ }^{\circ} \mathrm{C}$ for 3 days).

These results are in agreement with some work also reported by Bavykin ${ }^{55-56}$ who showed that the stability of the SNSs in solution could not necessarily be assumed and that it also depended on the $\mathrm{pH}$ and on the counter-anions present in solution. Playing with SNS aging to decrease $\mathrm{TiO}_{2}$ nanoparticle size is then an option to control the nanoneedles size, but it is far too timeconsuming. Indeed the exponential fit gives a characteristic time of dissolution of the SNSs of 20 days.

Influence of the medium initial $\mathrm{pH}$. The initial $\mathrm{pH}$ of the reaction medium was then adjusted to different values from 2 to 11 at least 3 times for each value and up to 8 times in some cases. In each case, the statistics on the NNs length were performed on at least 300 NPs from the TEM images, and the variation of the NNs length with the $\mathrm{pH}$ is illustrated in Figure 6. 


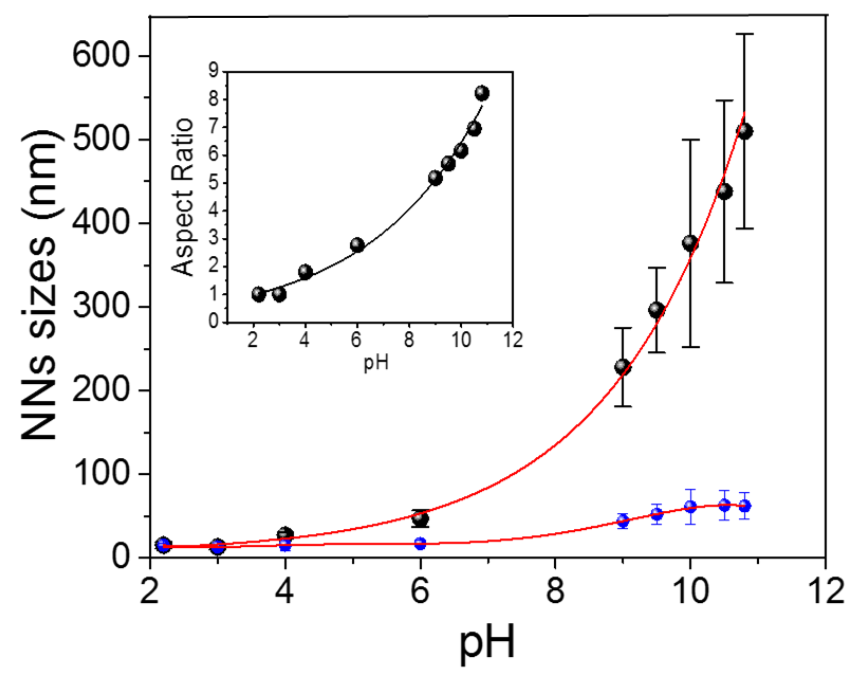

Figure 6. Variation of the sizes of nanoneedles with the $\mathrm{pH}$. Each dot represents an average of 3 to 8 experiments: black dots for NNs length, blue ones for NNs width (each experiment being representative of a statistic on at least $300 \mathrm{NPs}$ ), bars represent the statistic errors on these experiments; inset: variation of the $\mathrm{NNs}$ aspect ratio with the $\mathrm{pH}$. In all cases, lines are guides for the eye.

The variation of the $\mathrm{pH}$ can effectively adjust the length/width of the resulting NNs and control the NNs aspect ratio over a wide range from 1 at $\mathrm{pH} 2$, to 3 at $\mathrm{pH} 6$ and 8 at $\mathrm{pH}$ as high as 10.8 . In fact at $140^{\circ} \mathrm{C}$, the SNSs revealed to be very stable in concentrated basic media, and it was only when pHs were below 11 that it became possible to corrode them and generate long anatase NNs. As illustrated in Figure S1, the XRD patterns of these anatase nanoobjects only differ in the fact that there is a tendency at $\mathrm{pH} 9$ to form the brookite phase, with increasing brookite content with increasing $\mathrm{pH}$ values.

It has been proposed ${ }^{56}$ that the $\mathrm{pH}$-dependent transformation of the $\mathrm{SNSs}_{\text {to }} \mathrm{TiO}_{2}$ nanostructures could occur by the dissolution of the initial nanotubes at the edges accompanied by the simultaneous crystallization of $\mathrm{TiO}_{2}$ nanostructures, with a rate of the transformation at room temperature proportional to the steady-state concentration of dissolved $\mathrm{Ti}^{\mathrm{iV}}$, which is itself a function of the $\mathrm{pH}$. When performed in hydrothermal conditions, the crystal nucleation-growth 
is controlled by kinetics, rather than thermodynamics, leading to the formation of metastable anatase. ${ }^{51}$ These NNs exhibit a preferential direction along the [001] axis of anatase during the crystal growth, which can be easily explained by the selectivity of the constraint induced by the configuration and crystalline structure of the scrolled nanosheets used as precursors. Thus, the correlation between the crystalline structures of the SNSs and the resulting nanoobjects is crucial for the morphology of the later. Upon the hydrothermal treatment of the SNSs, the reaction proceeds with their partial dissolution followed by the rearrangement of the resulting bilayered fragments to form anatase nanoobjects; the size of these fragments being strongly $\mathrm{pH}-$ and temperature-dependent and controlling the final aspect ratio of the NNs. The preferential elongation [001] in the anatase is strongly dependent on the specific feature of the nanotubes. Both SNSs titanate and anatase have common structural characteristics ${ }^{87}$ : their lattices consist of octahedra sharing four edges and forming zigzag ribbons. Additionally, the titanate SNSs framework exhibits a majority of under-coordinated titanium sites located on the interior wall of the tube, ${ }^{88}$ and because of the $\mathrm{pH}$ the interplay between the ions in solution and the subsequently related possibility of generating Ti-O-Ti bonds, this framework shrinks locally by reducing the interlayer distances and rearranges, leading to the anatase $\mathrm{TiO}_{2}$ structure.

Even if adjusting the $\mathrm{pH}$ effectively allows a control of the NNs length through changing fragment size, the final NNs size distribution may still be a problem depending on the required applications, particularly for biological ones. The use of structuring agents (SAs) is a way to overcome this drawback and control the morphology of nanoobjects as well as their polydispersity, and many of these SAs have already been used in the literature: using basic ${ }^{15,17}$, 44, 64-65, 89-99 and acidic ${ }^{15,17,100-101}$ agents, on their own or in varied proportions; in hydrothermal ${ }^{1,}$ $5,7,18,33,37,41,46,50-51,54,72-73,83,91,102-108$ and non-hydrolytic ${ }^{5,16-17,41,50,54,106,109-111}$ processes. 
Influence of structuring agents: Among all those which were used, we focused our attention on triethanolamine (TEOA) and oleic acid (OA) which have been up to now used by Sugimoto et al. in the gel-sol process. ${ }^{65,95,98,112-115}$ These authors showed the influence and the role of TEOA as a trap in the release of the reactive $\mathrm{Ti}^{4+}$ species from the gel formed from titanium alkoxides before the formation of the $\mathrm{TiO}_{2}$ nanoparticles, at a temperature above $100{ }^{\circ} \mathrm{C}$. Our goal here was to apply this approach to a top-down approach, using the progressive destruction of the scrolled nanosheets as the source of " $\mathrm{Ti}^{4+"}$ and these two SAs separately or in combination under various $\mathrm{pH}$ conditions. Figure 7 illustrates the result of the synthesis of nanoneedles performed in the presence of TEOA and OA separately, at $\mathrm{pH} 9.8$. The same batch of starting scrolled nanosheets was used to make sure results were comparable. TEOA or OA was added to the scrolled nanosheets $(0.7 \mathrm{~g})$ and the $\mathrm{pH}$ adjusted to 9.8 with an aqueous solution of $0.1 \mathrm{~N}$ $\mathrm{NaOH}$. They were reacted in a Teflon-lined stainless steel autoclave, for 72 hours at $140{ }^{\circ} \mathrm{C}$ with 0,500 and $1000 \mu \mathrm{L}$ of the respective structuring agent $(3.76$ and $7.52 \mathrm{mmol}$ for TEOA (molar ratios between TEOA and Ti are 0.45 and 0.9 ) and 1.59 and $3.18 \mathrm{mmol}$ for OA (molar ratios between $\mathrm{OA}$ and $\mathrm{Ti}$ are 0.2 and 0.4 ). For the sake of clarity, results are presented as a function of the SA varying volumes. The TEM images on Figure 7a and 7c show that the morphology of the resulting objects does not change, whatever the chemical nature of the SA (TEOA or $\mathrm{OA}$ ) at the chosen $\mathrm{pH}$. A slight decrease of the average length seems to take place while keeping the standard deviation relatively high $(\sim 100 \mathrm{~nm})$ (Figure $7 \mathrm{~b}$ and $7 \mathrm{~d})$. 

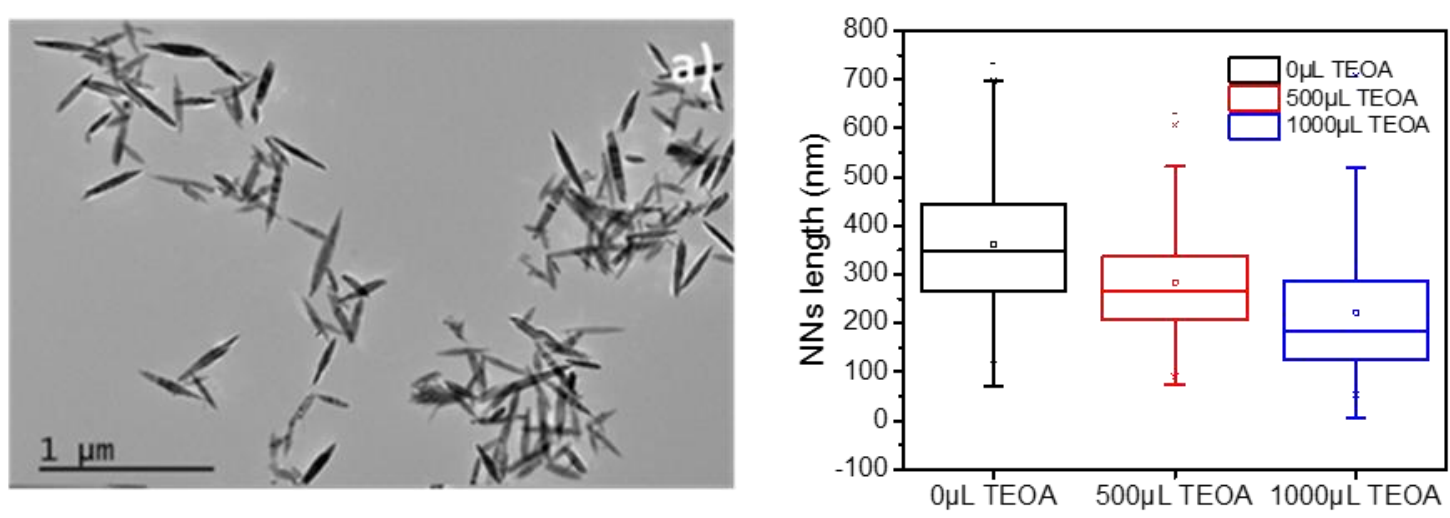

b)
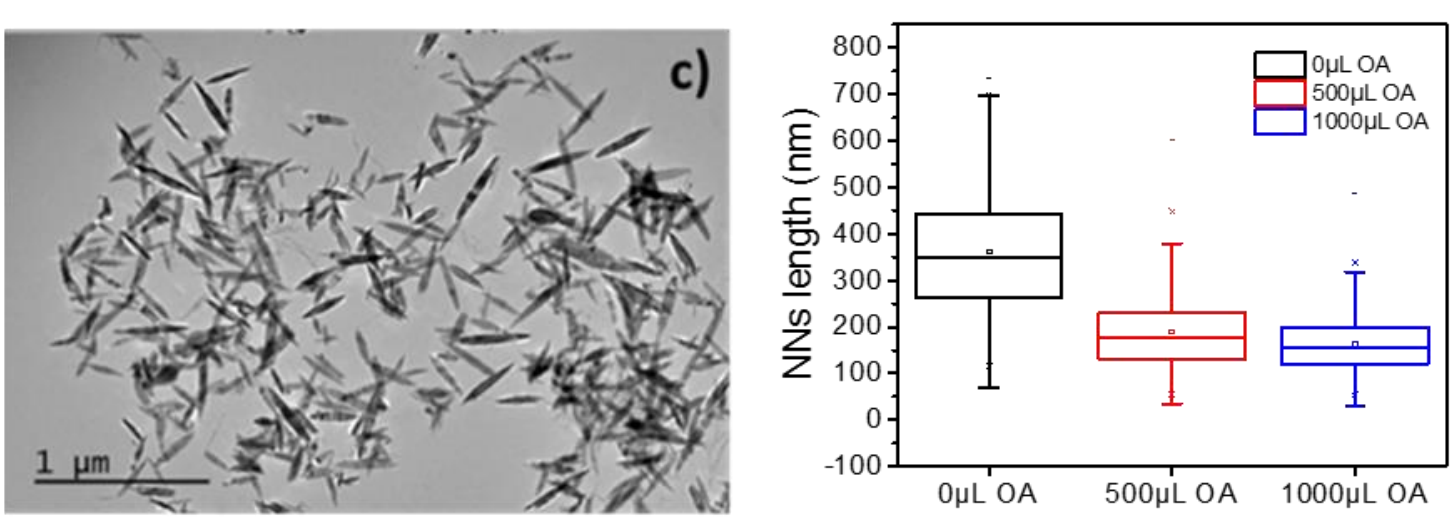

d)

Figure 7. TEM images of NNs prepared with $500 \mu \mathrm{L}$ of a) triethanolamine (TEOA) and c) oleic acid (OA); b) and d) NNs length distribution for an initial $\mathrm{pH}$ of 9.8 .

Experiments performed at different $\mathrm{pH}$ values confirmed the role of the SAs when used separately (Figure 8). TEOA containing both amino and $\mathrm{OH}$ groups is susceptible to interact with the SNSs in two potential ways: on the one hand, it can limit the growth rate of the planes parallel to the c-axis of $\mathrm{TiO}_{2}$ tetragonal crystal system because of its specific affinity for these planes in this $\mathrm{pH}$ range, ${ }^{98}$ its adsorption on the surface of $\mathrm{TiO}_{2}$ being negligible or extremely weak in neutral and acidic media ${ }^{112}$; on the other hand, it also contributes to the fragmentation of the titanate layer since for a given $\mathrm{pH}$ value of 9 , for example, the NNs length is divided by 2 in the presence of TEOA. Oleate anions provide both smaller NNs and reduced polydispersity. 


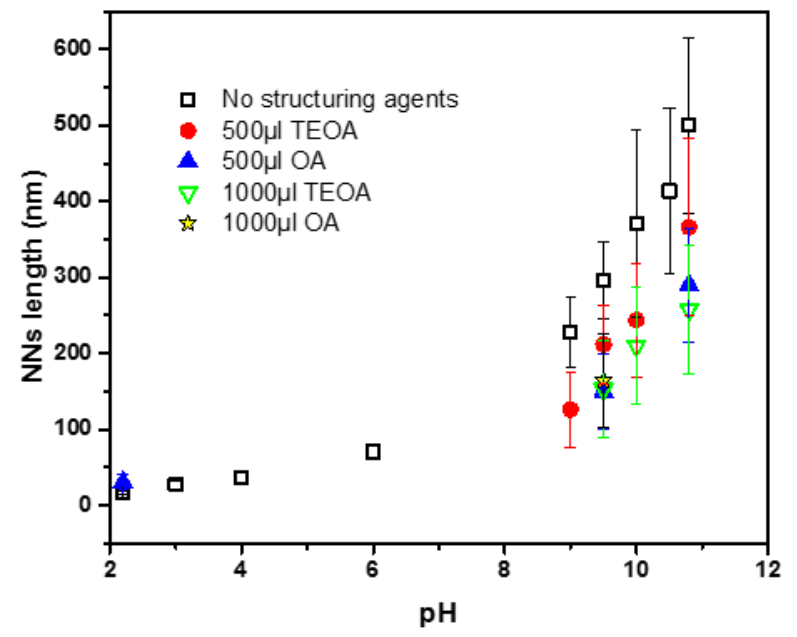

Figure 8. Average NNs length without (as in Figure 6) and with structuring agents (TEOA or OA). The error bars are obtained by means of at least 3 experiments.

High $\mathrm{pH}$ values $(>11.5)$ did inhibit the formation of NNs in the presence of TEOA, probably because the SNSs were too stable in these conditions and the rate of dissolution of the SNSs and formation in solution of the titanium hydroxide aquo complexes postulated to induce the nucleation of $\mathrm{TiO}_{2}$ by this pathway is too low. ${ }^{113}$ Indeed, instead of starting from an amorphous gel of $\mathrm{Ti}(\mathrm{OH})_{\mathrm{x}}$ as in Sugimoto's case ${ }^{65,98}$ where the OH group can be easily replaced by TEOA or OA, the process here starts from scrolled nanosheets which are first partially dissolved, and then restacked in the right configuration. It should be added that TEOA has also been observed to act as a capping agent. ${ }^{116-117}$

In the low $\mathrm{pH}$ range $(\mathrm{pH}<6)$, the NPs exhibit the identical size and shape as in the absence of structuring agent (Supporting Information Figure S2).

Influence of the combination of the structuring agents: We then combined these two SAs fixing the quantities of TEOA at $500 \mu \mathrm{L}(3.76 \mathrm{mmol})$ and $\mathrm{OA}$ at $500 \mu \mathrm{L}(1.59 \mathrm{mmol})$ and varied the initial $\mathrm{pH}$ of the reaction mixture (Figure 9). 


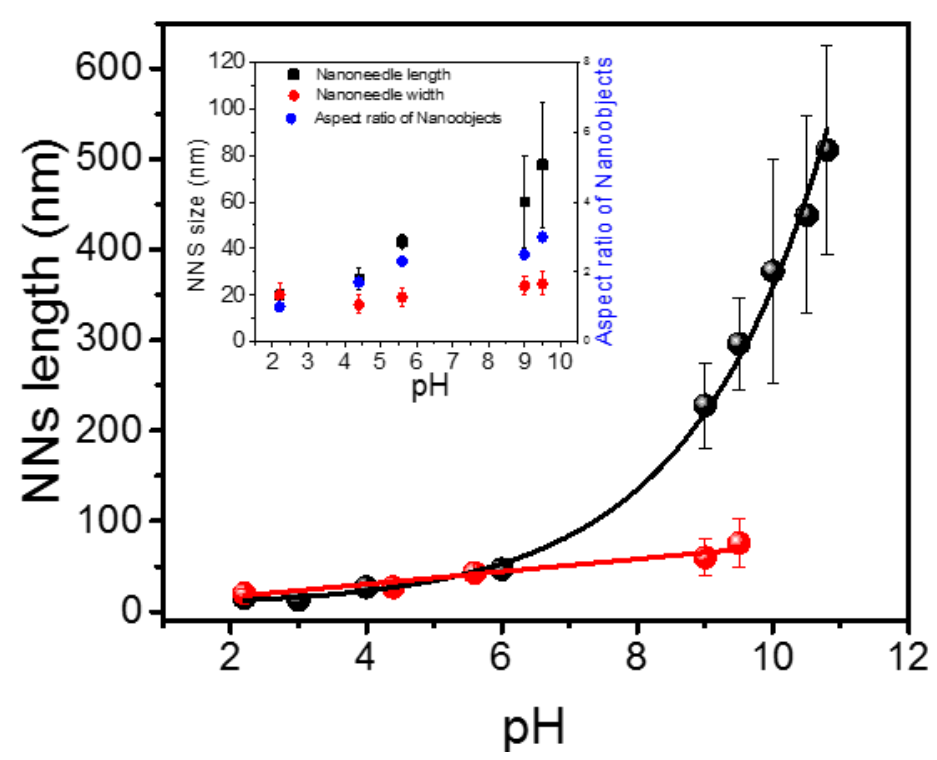

Figure 9. Variation of the NNs length, with the $\mathrm{pH}$ of the reaction medium in the absence (black dots) and in the presence of $500 \mu \mathrm{L}$ of both SAs (red dots). Results represent the averages of statistics of at least 300 NPs for each of the 3 sets of experiments per data point. Inset variation of the width and aspect ratio of the same objects obtained in the presence of the two SAs. Lines are guides for the eye.

Figure 9 compares the size and aspect ratio of the resulting objects as a function of $\mathrm{pH}$ in the presence and absence of the SAs. This figure effectively illustrates the influence of the combination of these two SAs on the size and morphology of the resulting objects. The major impact of this concomitant use is visible under basic conditions (9-10.5) where a higher control over the length as well as over the size distribution of the objects can be performed (compare with Figure 8). Furthermore the NNs shape was a rod-like one with flatter extremities in the low $\mathrm{pH}$ range, as illustrated in Figure 10, confirming the affinity of the carboxylate ions for the (001) face and their blocking effect on the crystal growth. Nanorods with various sizes and aspect ratios could be obtained by playing with the ratio between the SNSs and the capping agents, while the absence of these shape controllers led to a mixture of less-specific nanoobjects (Figure 10a). 

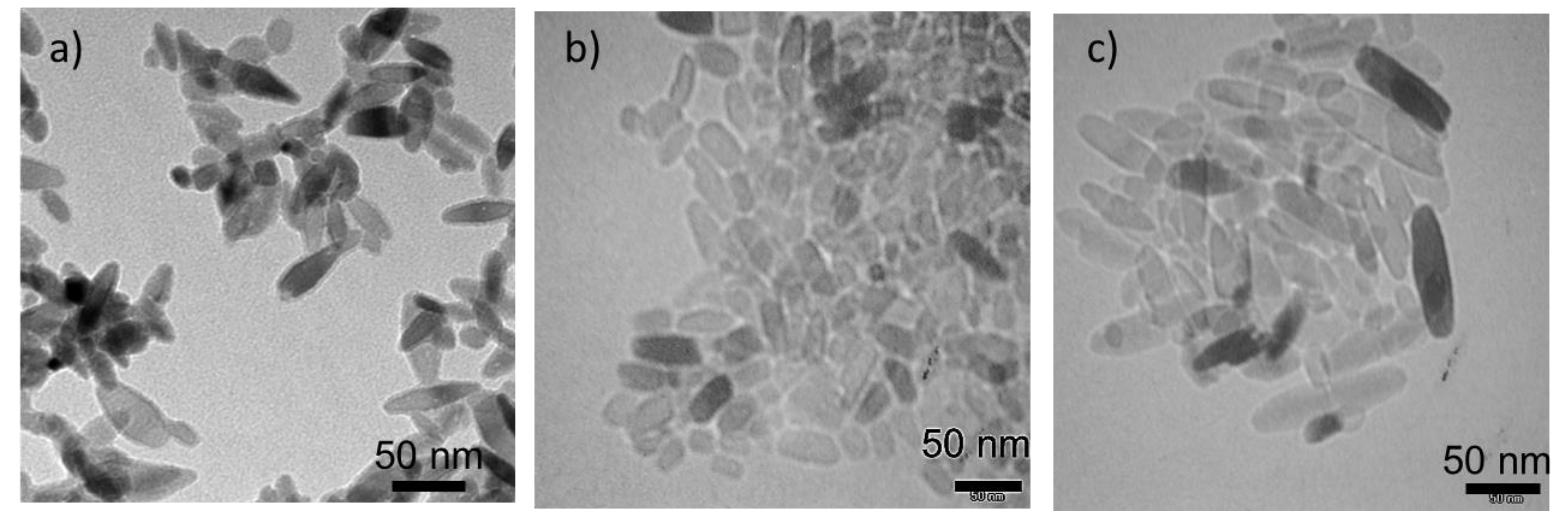

Figure 10. Example of TEM images of $\mathrm{TiO}_{2}$ nanorods obtained at $\mathrm{pH} 4.4$ : a) in the absence of any capping agent; and b) in the presence of $500 \mu \mathrm{L}(3.76 \mathrm{mmol})$ of TEOA and $500 \mu \mathrm{L}(1.59$ mmol) OA starting with $2 \mathrm{~g}$ of SNSs (NRs length $34( \pm 10)$, width: $15( \pm 5)$ aspect ratio: 2 and c) starting with $0.7 \mathrm{~g}$ of SNSs (NRs length 73 ( \pm 15$)$, width: $21( \pm 8)$ aspect ratio: 3$)$.

A $\mathrm{pH}$ value of 10.7 which is a usual value given in the literature for the action of amines as structuring agents, ${ }^{98}$ revealed to be detrimental in the presence of oleate since the conversion of SNSs was not complete (see Figure S3 in supporting information), and the efficiency became even worse with increasing amounts of oleate. It could be proposed that using a $\mathrm{pH}$ above a given value prevails on any other parameter for the shape control of NPs. ${ }^{65}$

We then focused on $\mathrm{pH} 9.5$, which revealed to be the autogenous $\mathrm{pH}$ of the resulting mixture after stabilization with $500 \mu \mathrm{L}$ of TEOA and varied the ratio between TEOA and OA increasing the volume of OA from 0 to $1600 \mu \mathrm{L}$. Figure 11 shows characteristic TEM images of particles obtained with different amounts of OA. It illustrates the synergetic effect of the combined use of these two structuring agents and shows the influence of the OA amount on not only the length of NNs but also on their shape since they turn into nanorods and finally give nanocuboid-like particles (Figures 11a,b,c). This is commonly explained by the selective binding of the OA to the anatase $(001)$ face ${ }^{111,118}$ which controls its growth. 

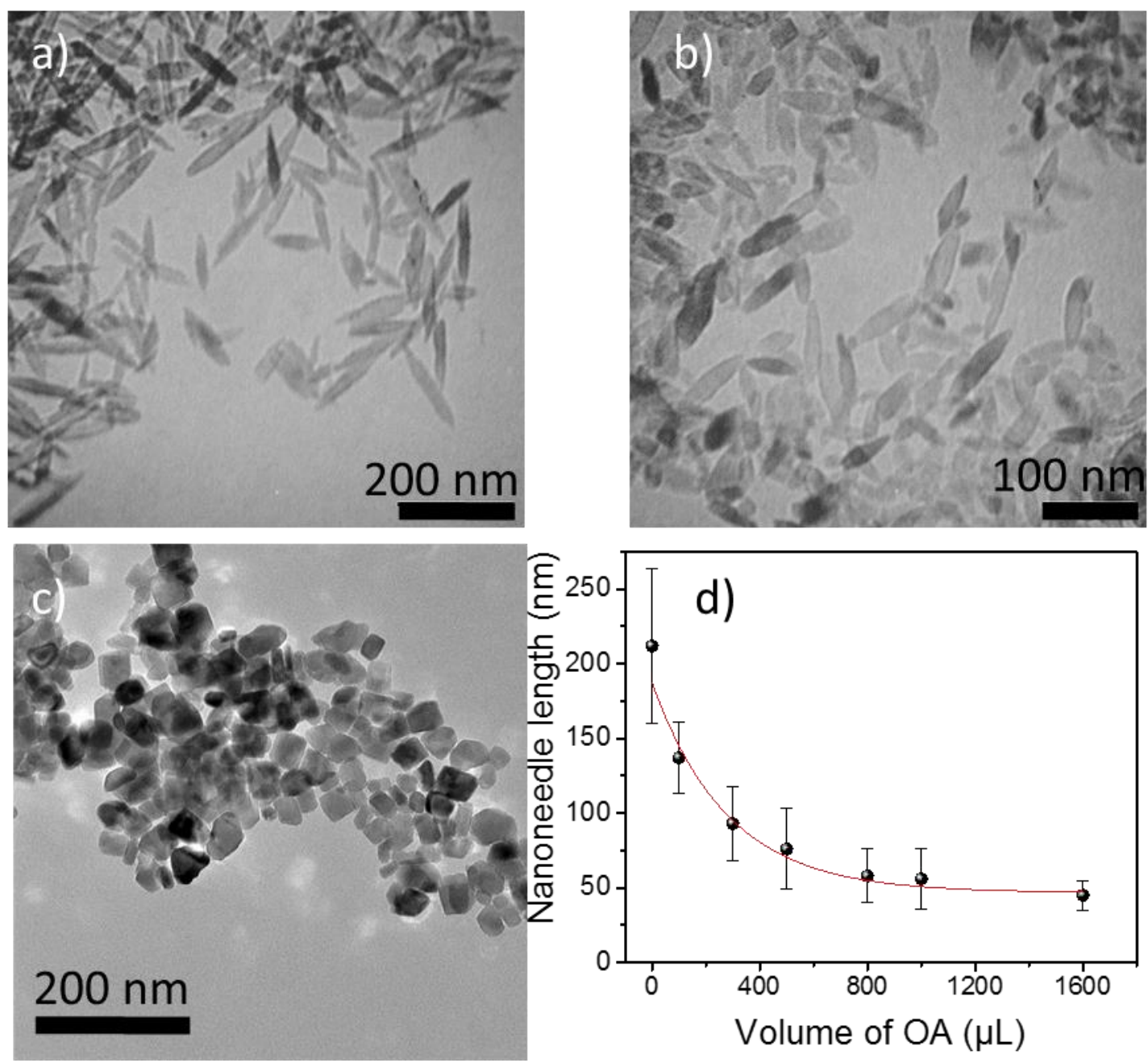

Figure 11. TEM images of the different shapes of particles synthesized using $500 \mu \mathrm{L}$ of TEOA at pH 9.5 and respectively: a) $0 \mu \mathrm{L}$ of OA, b) $500 \mu \mathrm{L}$ of OA, c) $800 \mu \mathrm{L}$ of OA; d) Variation of the NNs length with the amount of oleic acid at a fixed concentration of TEOA (500 $\mu \mathrm{L})$ at $\mathrm{pH}$ 9.5 on a set of a total of 3 experiments per point.

In this top-down process, the nanosheets can react as follows: (i) depending on the $\mathrm{pH}$, their dimensions are reduced and they are partially dissolved leading to the Ti(IV) complex soluble in the reaction mixture in equilibrium with small fragments, which can then rearrange. The structuring agents participate in the control of these fragments size. They also tune the growth rate of the specific crystal planes by their specific adsorption under different $\mathrm{pH}$ conditions (parallel (for TEOA) or perpendicular (for OA) to the $c$-axis, ${ }^{65,}{ }^{99}$ ). (ii) In the presence of the SAs the dissolved titanium based octahedra complexes can also agglomerate and exhibit 
controlled growth as do SAs, as described by Sugimoto. (iii) Or both processes can take place in a ratio difficult to estimate. Different sets of 3 tests per experiment were performed at $\mathrm{pH} 9.5$ (Figure 11d) to determine repeatability, reproducibility, and statistical parameters. The decrease of the size of the nanoneedles with increase of the oleic acid quantity was confirmed and clearly indicated the crucial role played by this capping agent in the presence of TEOA.

The concomitant use of these two SAs allows the control of not only the morphology but also the purity of the anatase crystal phase by preventing the formation of the brookite-type $\mathrm{TiO}_{2}$, which is often produced (even if only a few \%) in the presence of $\mathrm{Na}^{+}$under hydrothermal conditions (Figure 12). ${ }^{51}$

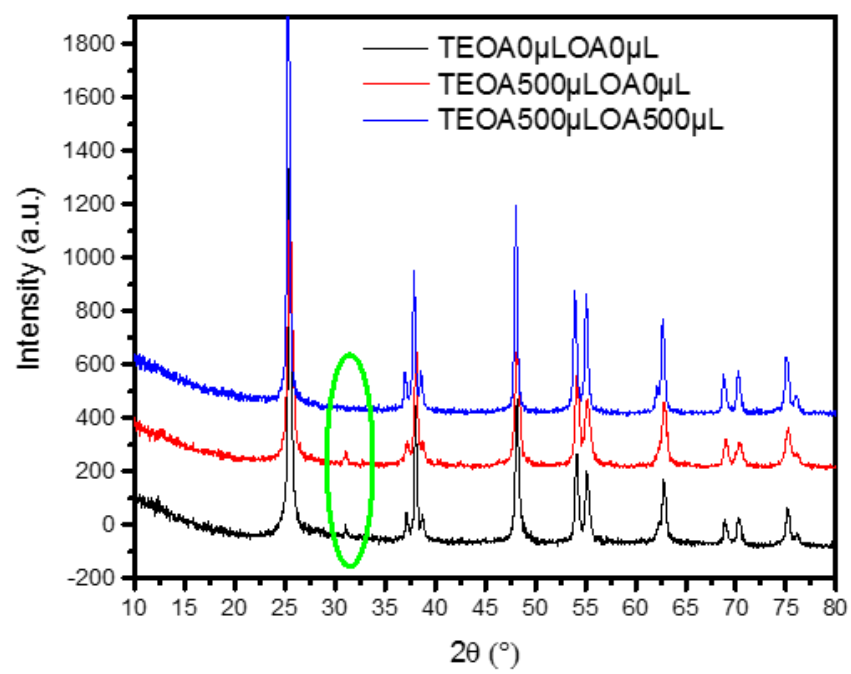

Figure 12. XRD pattern of NNs synthesized at initial pH 9.5 with $(-)$ no structuring agent; $(-)$ $500 \mu \mathrm{L}$ of TEOA and $0 \mu \mathrm{L}$ of OA, (-) $500 \mu \mathrm{L}$ of TEOA and $500 \mu \mathrm{L}$ of OA.

HRTEM was performed on both NNs and NRs morphologies, and Figure 13 shows an example of a nearly perfect $\mathrm{NN}$ obtained at $\mathrm{pH} 9.5$ in the presence of the two SAs. The nature of the clearly visible atomic planes is deduced from the indexation of the Fast Fourier Transform (FFT) of the image. In addition, based on the orientation deduced from the FFT, a simulated image has been calculated taking into account the characteristics of the microscope. This 
calculated image is inserted into the experimental one and the good agreement between both images confirms the structure and the orientation of the studied material (white arrow). The particle is elongated along the [001] direction which is consistent with the prediction ${ }^{15,119}$ and with the already published finding. ${ }^{15}$

Indeed, all the observed particles are elongated along the same direction. In this nano-crystal, the facets are parallel to the $\{101\}$ planes. However, this is not the case for most of the particles.

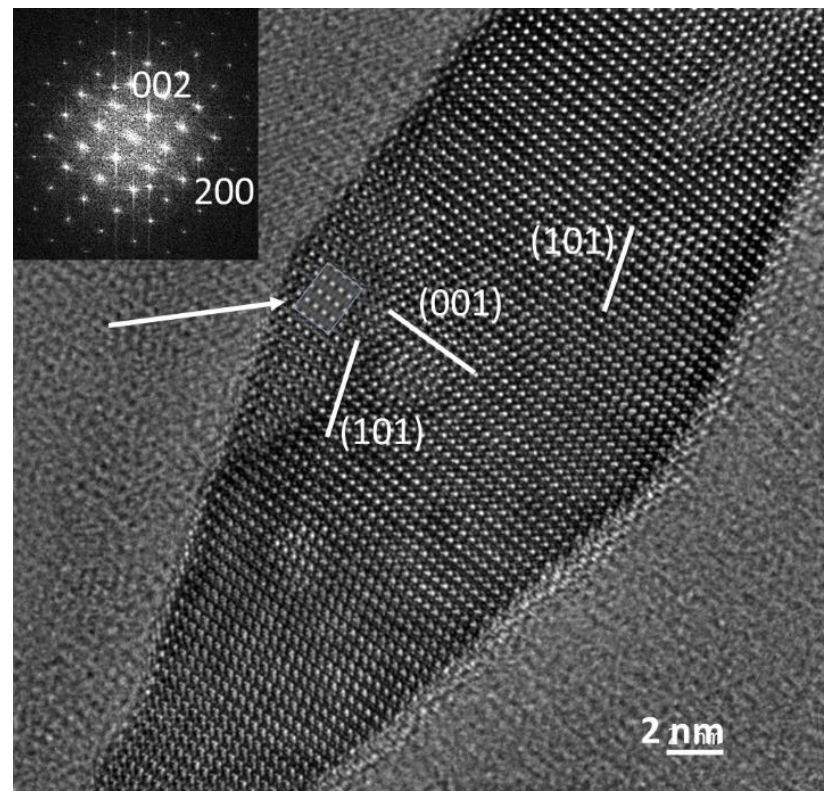

Figure 13. HRTEM image and Fast Fourier Transform of a perfect NN. The inserted image in the particle is a simulated image along the [010] zone axis at Scherer defocus for a $5 \mathrm{~nm}$ thickness.

A typical example is shown in Figure 14. The outer faces of the crystal are composed of nanofacets belonging to the $\{101\}$ planes. Their length is variable making it possible to accommodate different geometries from one crystal to another. 


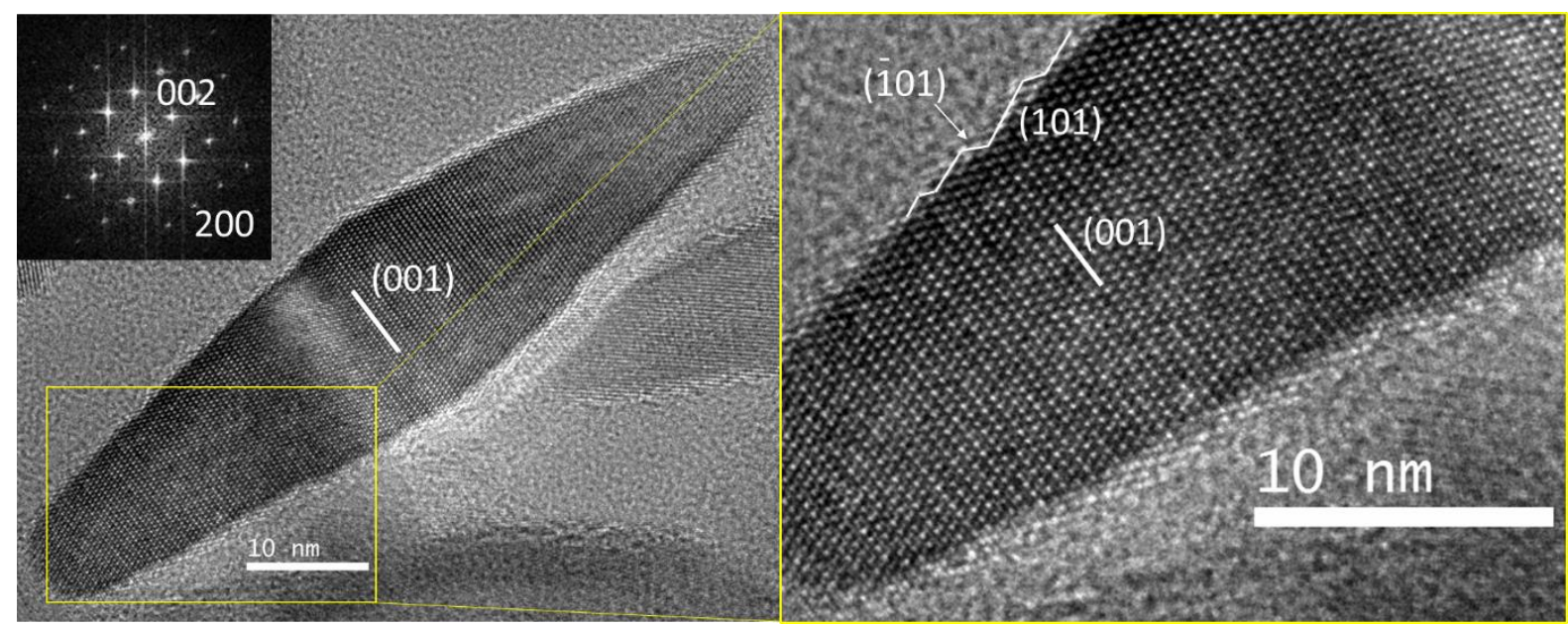

Figure 14. TEM image of a typical crystal in a NN form; inset: selected area electron diffraction pattern b) HRTEM image of the same NN showing a saw-tooth-like organization of the (101) planes of the external facet of the crystal.

High resolution images of nanorods have also been obtained (Figure 15). As previously for the NNs, the nanorods are elongated along the [001] direction, but the main external facets are this time parallel to the (100) planes. The curved end of the nanorods is composed of sequences of (101) and (-101) planes as illustrated in the figure.

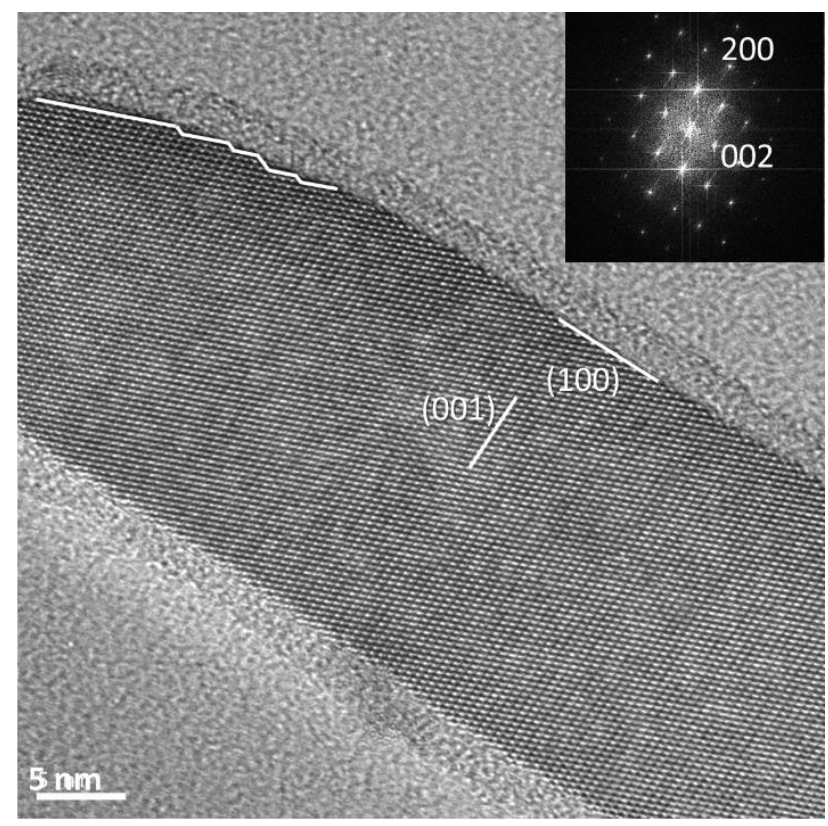

Figure 15. HRTEM image of a typical crystal in a nanorod shape. 


\section{CONCLUSION:}

To conclude, in this paper we were able to generate a large family of anatase phase nanoobjects with typical sizes from 15 to $700 \mathrm{~nm}$ and aspect ratios from 1 to 8 , through a wet chemistry process starting from titanate scrolled nanosheets. Morphology was tailored by playing with different parameters such as (i) the age of the SNSs, (ii) mild hydrothermal temperature $140^{\circ} \mathrm{C}$, (iii) a wide $\mathrm{pH}$ range 2-11. The concomitant use of structuring agents such as triethanol amine and oleic acid during the hydrothermal process proved to be an additional convenient way to master the phase transformation and control the size and shape as well as the polydispersity of the targeted nanoobjects in basic media.

\section{ACKNOWLEDGEMENTS}

The authors want to acknowledge Eric Lebraud (ICMCB) for XRD measurements. All the TEM observations were performed on the microscopes of the Plateforme Aquitaine de Caractérisation des Matériaux (UMS 3626, CNRS - Université de Bordeaux, Pessac, France) and at the Bordeaux Imaging Center for some of the samples. P25 from Evonik was a generous gift from Evonik Company which is here strongly acknowledged. Financial support from the China Scholarship Council (CSC) of the People's Republic of China (grant to Q. Bai), the French ANR program TITAMIUMS (PhD Grant to Q. Le Trequesser) to the Idex and the University of Bordeaux, and the CNRS are gratefully acknowledged.

Supporting Information Available: (XRD patterns of $\mathrm{TiO}_{2}$ anatase NNS prepared at different initial $\mathrm{pH}$ values. TEM images of nanoparticles prepared with $500 \mu \mathrm{L}$ of oleic acid (OA) at an 
initial $\mathrm{pH}$ of 2. TEM images of the result of nanoneedles synthesis using $500 \mu \mathrm{L}$ of TEOA at initial $\mathrm{pH} 10.7$ and a) $0 \mu \mathrm{L}$ of $\mathrm{OA}$, b) $500 \mu \mathrm{L}$ of $\mathrm{OA}$, c) $800 \mu \mathrm{L}$ of OA showing the adverse effect of the concomitant use of high $\mathrm{pH}$ and oleate structuring agent.. This material is available free of charge via the Internet at http://pubs.acs.org.

\section{REFERENCES}

1. Gomathi Devi, L.; Kavitha, R., A Review on Plasmonic Metal-TiO 2 Composite for Generation, Trapping, Storing and Dynamic Vectorial Transfer of Photogenerated Electrons across the Schottky Junction in a Photocatalytic System. Appl. Surf. Sci. 2016, 360, 601-622.

2. Karapati, S.; Giannakopoulou, T.; Todorova, N.; Boukos, N.; Dimotikali, D.; Trapalis, C., Eco-Efficient $\mathrm{TiO}_{2}$ Modification for Air Pollutants Oxidation. Appl. Catal., B 2015, 176$177,578-585$.

3. Kapilashrami, M.; Zhang, Y.; Liu, Y.-S.; Hagfeldt, A.; Guo, J., Probing the Optical Property and Electronic Structure of $\mathrm{TiO}_{2}$ Nanomaterials for Renewable Energy Applications. Chem. Rev. 2014, 114, 9662-9707.

4. De Angelis, F.; Di Valentin, C.; Fantacci, S.; Vittadini, A.; Selloni, A., Theoretical Studies on Anatase and Less Common $\mathrm{TiO}_{2}$ Phases: Bulk, Surfaces, and Nanomaterials. Chem. Rev. 2014, 114, 9708-9753.

5. Liu, G.; Yang, H. G.; Pan, J.; Yang, Y. Q.; Lu, G. Q.; Cheng, H.-M., Titanium Dioxide Crystals with Tailored Facets. Chem. Rev. 2014, 114, 9559-9612.

6. Linsebigler, A. L.; Lu, G.; Yates, J. T., Photocatalysis on $\mathrm{TiO}_{2}$ Surfaces: Principles, Mechanisms, and Selected Results. Chem. Rev. 1995, 95, 735-758.

7. Schneider, J.; Matsuoka, M.; Takeuchi, M.; Zhang, J.; Horiuchi, Y.; Anpo, M.; Bahnemann, D. W., Understanding $\mathrm{TiO}_{2}$ Photocatalysis: Mechanisms and Materials. Chem. Rev. 2014, 114, 9919-9986.

8. $\quad$ Long, J.; Chang, H.; Gu, Q.; Xu, J.; Fan, L.; Wang, S.; Zhou, Y.; Wei, W.; Huang, L.; Wang, X.; Liu, P.; Huang, W., Gold-Plasmon Enhanced Solar-to-Hydrogen Conversion on the \{001\} Facets of Anatase TiO2 Nanosheets. Energy \& Environ. Sci. 2014, 7, 973-977.

9. Wang, H.; Guo, Z.; Wang, S.; Liu, W., One-Dimensional Titania Nanostructures: Synthesis and Applications in Dye-Sensitized Solar Cells. Thin Solid Films 2014, 558, 1-19.

10. Bai, J.; Zhou, B., Titanium Dioxide Nanomaterials for Sensor Applications. Chem. Rev. 2014, 114, 10131-10176.

11. Jeynes, J. C. G.; Jeynes, C.; Palitsin, V.; Townley, H. E., Direct Quantification of Rare Earth Doped Titania Nanoparticles in Individual Human Cells. Nanotechnology 2016, 27, 285103/1-285103/8.

12. Fei Yin, Z.; Wu, L.; Gui Yang, H.; Hua Su, Y., Recent Progress in Biomedical Applications of Titanium Dioxide. Phys. Chem. Chem. Phys. 2013, 15, 4844-4858.

13. Tong, R.; Liu, C.; Xu, Z.; Kuang, Q.; Xie, Z.; Zheng, L., Efficiently Enhancing Visible Light Photocatalytic Activity of Faceted $\mathrm{TiO}_{2}$ Nanocrystals by Synergistic Effects of CoreShell Structured Au@CdS Nanoparticles and Their Selective Deposition. ACS Appl. Mater. Interfaces 2016, 8, 21326-21333. 
14. Fujishima, A.; Zhang, X.; Tryk, D. A., $\mathrm{TiO}_{2}$ Photocatalysis and Related Surface Phenomena. Surf. Sci. Rep. 2008, 63, 515-582.

15. D'Arienzo, M.; Carbajo, J.; Bahamonde, A.; Crippa, M.; Polizzi, S.; Scotti, R.; Wahba, L.; Morazzoni, F., Photogenerated Defects in Shape-Controlled $\mathrm{TiO}_{2}$ Anatase Nanocrystals: A Probe to Evaluate the Role of Crystal Facets in Photocatalytic Processes. J. Am. Chem. Soc. 2011, 133, 17652-17661.

16. Liu, J.; Olds, D.; Peng, R.; Yu, L.; Foo, G. S.; Qian, S.; Keum, J.; Guiton, B. S.; Wu, Z.; Page, K., Quantitative Analysis of the Morphology of $\{101\}$ and $\{001\}$ Faceted Anatase $\mathrm{TiO}_{2}$ Nanocrystals and Its Implication on Photocatalytic Activity. Chem. Mater. 2017, 29, 5591-5604.

17. Calatayud, D. G.; Rodríguez, M.; Jardiel, T., Controlling the Morphology of Tio2 Nanocrystals with Different Capping Agents. Bol. Soc. Esp. Ceram. Vidrio 2015, 54, 159-165. 18. Zhang, H.; Banfield, J. F., Structural Characteristics and Mechanical and Thermodynamic Properties of Nanocrystalline $\mathrm{TiO}_{2}$. Chem. Rev. 2014, 114, 9613-9644.

19. Runkel, M.-C.; Wittich, O.; Feldhoff, A.; Wark, M.; Bredow, T., Theoretical and Experimental Study of Anatase Nanotube Formation Via Sodium Titanate Intermediates. $J$. Phys. Chem. C 2015, 119, 5048-5054.

20. Mao, Y.; Wong, S. S., Size- and Shape-Dependent Transformation of Nanosized Titanate into Analogous Anatase Titania Nanostructures. J. Am. Chem. Soc. 2006, 128, 8217 8226.

21. Yang, H. G.; Liu, G.; Qiao, S. Z.; Sun, C. H.; Jin, Y. G.; Smith, S. C.; Zou, J.; Cheng,

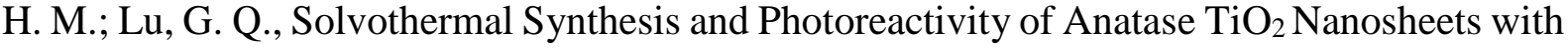
Dominant $\{001\}$ Facets. J. Am. Chem. Soc. 2009, 131, 4078-4083.

22. Kumar, S. G.; Rao, K. S. R. K., Polymorphic Phase Transition among the Titania Crystal Structures Using a Solution-Based Approach: From Precursor Chemistry to Nucleation Process. Nanoscale 2014, 6, 11574-11632.

23. Djurišić, A. B.; Leung, Y. H.; Ng, A. M. C.; Xu, X. Y.; Lee, P. K. H.; Degger, N.; Wu, R. S. S., Toxicity of Metal Oxide Nanoparticles: Mechanisms, Characterization, and Avoiding Experimental Artefacts. Small 2015, 11, 26-44.

24. Hsieh, S.-F.; Bello, D.; Schmidt, D. F.; Pal, A. K.; Stella, A.; Isaacs, J. A.; Rogers, E. J., Mapping the Biological Oxidative Damage of Engineered Nanomaterials. Small 2013, 9, $1853-1865$.

25. Johnston, H.; Hutchison, G.; Christensen, F.; Peters, S.; Hankin, S.; Stone, V., Identification of the Mechanisms That Drive the Toxicity of $\mathrm{TiO}_{2} \mathrm{Particulates}$ The Contribution of Physicochemical Characteristics. Part. Fibre Toxicol. 2009, 6, 33.

26. Lewinski, N.; Colvin, V.; Drezek, R., Cytotoxicity of Nanoparticles. Small 2008, 4, 26-

49.

27. Li, M.; Yin, J.-J.; Wamer, W. G.; Lo, Y. M., Mechanistic Characterization of Titanium Dioxide Nanoparticle-Induced Toxicity Using Electron Spin Resonance. J. Food Drug Anal. 2014, 22, 76-85.

28. Mikolajczyk, A.; Sizochenko, N.; Mulkiewicz, E.; Malankowska, A.; Nischk, M.; Jurczak, P.; Hirano, S.; Nowaczyk, G.; Zaleska-Medynska, A.; Leszczynski, J.; Gajewicz, A.; Puzyn, T., Evaluating the Toxicity of $\mathrm{TiO}_{2}$-Based Nanoparticles to Chinese Hamster Ovary Cells and Escherichia Coli: A Complementary Experimental and Computational Approach. Beilstein J. Nanotechnol. 2017, 8, 2171-2180.

29. Minetto, D.; Libralato, G.; Volpi Ghirardini, A., Ecotoxicity of Engineered $\mathrm{TiO}_{2}$ Nanoparticles to Saltwater Organisms: An Overview. Environ. Int. 2014, 66, 18-27.

30. Setyawati, M. I.; Tay, C. Y.; Leong, D. T., Mechanistic Investigation of the Biological Effects of $\mathrm{SiO}_{2}, \mathrm{TiO}_{2}$, and Zno Nanoparticles on Intestinal Cells. Small 2015, 11, 3458-3468. 
31. Setyawati, M. I.; Tay, C. Y.; Leong, D. T., Nanotoxicity: Mechanistic Investigation of the Biological Effects of Sio2, $\mathrm{TiO}_{2}$, and Zno Nanoparticles on Intestinal Cells (Small 28/2015). Small 2015, 11, 3390-3390.

32. Simon, M.; Barberet, P.; Delville, M.-H.; Moretto, P.; Seznec, H., Titanium Dioxide Nanoparticles Induced Intracellular Calcium Homeostasis Modification in Primary Human Keratinocytes. Towards an in Vitro Explanation of Titanium Dioxide Nanoparticles Toxicity. Nanotoxicology 2010, 126-140.

33. Bavykin, D. V.; Walsh, F. C., Elongated Titanate Nanostructures and Their Applications. Eur. J. Inorg. Chem. 2009, 2009, 977-997.

34. Botta, C.; Labille, J.; Auffan, M.; Borschneck, D.; Miche, H.; Cabié, M.; Masion, A.; Rose, J.; Bottero, J.-Y., TiO 2 -Based Nanoparticles Released in Water from Commercialized Sunscreens in a Life-Cycle Perspective: Structures and Quantities. Environmental Pollution 2011, 159, 1543-1550.

35. Cai, K.; Hou, Y.; Hu, Y.; Zhao, L.; Luo, Z.; Shi, Y.; Lai, M.; Yang, W.; Liu, P., Correlation of the Cytotoxicity of $\mathrm{TiO}_{2}$ Nanoparticles with Different Particle Sizes on a Sub200-Nm Scale. Small 2011, 7, 3026-3031.

36. Chen, J.; Zhou, H.; Santulli, A. C.; Wong, S. S., Evaluating Cytotoxicity and Cellular Uptake from the Presence of Variously Processed $\mathrm{TiO}_{2}$ Nanostructured Morphologies. Chem. Res. Toxicol. 2010, 23, 871-879.

37. Lee, K.; Mazare, A.; Schmuki, P., One-Dimensional Titanium Dioxide Nanomaterials: Nanotubes. Chem. Rev. 2014, 114, 9385-9454.

38. Liu, X.; Sui, B.; Sun, J., Size- and Shape-Dependent Effects of Titanium Dioxide Nanoparticles on the Permeabilization of the Blood-Brain Barrier. J. Mater. Chem. B 2017, 5, 9558-9570.

39. Rajh, T.; Dimitrijevic, N. M.; Bissonnette, M.; Koritarov, T.; Konda, V., Titanium Dioxide in the Service of the Biomedical Revolution. Chem. Rev. 2014, 114, 10177-10216.

40. Townley, H. E.; Rapa, E.; Wakefield, G.; Dobson, P. J., Nanoparticle Augmented Radiation Treatment Decreases Cancer Cell Proliferation. Nanomedicine 2012, 8, 526-536.

41. Truong, Q. D.; Dien, L. X.; Vo, D.-V. N.; Le, T. S., Controlled Synthesis of Titania Using Water-Soluble Titanium Complexes: A Review. J. Solid State Chem. 2017, 251, 143 163.

42. Victoria, K.; Mohamed, I.; A., L. S.; Salmorin, B. E.; Evelyn, N.; Cuida, M. M.; Elena, C. D.; R., C. M., Nano- $\mathrm{TiO}_{2}$ Penetration of Oral Mucosa: In Vitro Analysis Using 3d Organotypic Human Buccal Mucosa Models. J Oral Pathol. Med. 2017, 46, 214-222.

43. Yu, K. O.; Grabinski, C. M.; Schrand, A. M.; Murdock, R. C.; Wang, W.; Gu, B.; Schlager, J. J.; Hussain, S. M., Toxicity of Amorphous Silica Nanoparticles in Mouse Keratinocytes. J. Nanopart. Res. 2009, 11, 15-24.

44. Amoli, V.; Bhat, S.; Maurya, A.; Banerjee, B.; Bhaumik, A.; Sinha, A. K., Tailored Synthesis of Porous $\mathrm{TiO}_{2}$ Nanocubes and Nanoparallelepipeds with Exposed $\{111\}$ Facets and Mesoscopic Void Space: A Superior Candidate for Efficient Dye-Sensitized Solar Cells. ACS Appl. Mater. Interfaces 2015, 7, 26022-26035.

45. Yang, M.-H.; Chen, P.-C.; Tsai, M.-C.; Chen, T.-T.; Chang, I. C.; Chiu, H.-T.; Lee, C.Y., Anatase and Brookite $\mathrm{TiO}_{2}$ with Various Morphologies and Their Proposed Building Block. CrystEngComm 2014, 16, 441-447.

46. Ray, C.; Pal, T., Recent Advances of Metal-Metal Oxide Nanocomposites and Their Tailored Nanostructures in Numerous Catalytic Applications. J. Mater. Chem. A 2017, 5, 94659487.

47. Roy, N.; Park, Y.; Sohn, Y.; Leung, K. T.; Pradhan, D., Green Synthesis of Anatase $\mathrm{TiO}_{2}$ Nanocrystals with Diverse Shapes and Their Exposed Facets-Dependent Photoredox Activity. ACS Appl. Mater. Interfaces 2014, 6, 16498-16507. 
48. Yun, H. J.; Lee, H.; Joo, J. B.; Kim, W.; Yi, J., Influence of Aspect Ratio of $\mathrm{TiO}_{2}$ Nanorods on the Photocatalytic Decomposition of Formic Acid. J. Phys. Chem. C 2009, 113, 3050-3055.

49. Yang, M.-H.; Chen, P.-C.; Tsai, M.-C.; Chen, T.-T.; Chang, I. C.; Chiu, H.-T.; Lee, C.Y., Alkali Metal Ion Assisted Synthesis of Faceted Anatase $\mathrm{TiO}_{2}$. CrystEngComm 2013, 15, 2966-2971.

50. Cargnello, M.; Gordon, T. R.; Murray, C. B., Solution-Phase Synthesis of Titanium Dioxide Nanoparticles and Nanocrystals. Chem. Rev. 2014, 114, 9319-9345.

51. Nian, J.-N.; Teng, H., Hydrothermal Synthesis of Single-Crystalline Anatase $\mathrm{TiO}_{2}$ Nanorods with Nanotubes as the Precursor. J. Phys. Chem. B 2006, 110, 4193-4198.

52. Kasuga, T.; Hiramatsu, M.; Hoson, A.; Sekino, T.; Niihara, K., Formation of Titanium Oxide Nanotube. Langmuir 1998, 14, 3160-3163.

53. Kasuga, T.; Hiramatsu, M.; Hoson, A.; Sekino, T.; Niihara, K., Titania Nanotubes Prepared by Chemical Processing. Adv. Mater. 1999, 11, 1307-1311.

54. Chen, X.; Mao, S. S., Titanium Dioxide Nanomaterials: Synthesis, Properties, Modifications, and Applications. Chem. Rev. 2007, 107, 2891-2959.

55. Bavykin, D. V.; Friedrich, J. M.; Lapkin, A. A.; Walsh, F. C., Stability of Aqueous Suspensions of Titanate Nanotubes. Chem. Mater. 2006, 18, 1124-1129.

56. Bavykin, D. V.; Lapkin, A. A.; Friedrich, J. M.; Walsh, F. C. In Acid Transformation of $\mathrm{TiO}_{2}$ Nanotubes to Nanoparticles, Nano Science and Technology Institute: 2005; pp 655-658.

57. Eslami, H.; Moztarzadeh, F.; Kashi, T. S. J.; Khoshroo, K.; Tahriri, M., Hydrothermal Synthesis and Characterization of $\mathrm{TiO}_{2}$-Derived Nanotubes for Biomedical Applications. Synth. React. Inorg., Met.-Org., Nano-Met. Chem. 2016, 46, 1149-1156.

58. Li, Q.; Lu, G., Controlled Synthesis and Photocatalytic Investigation of DifferentShaped One-Dimensional Titanic Acid Nanomaterials. J. Power Sources 2008, 185, 577-583.

59. Nakahira, A.; Kubo, T.; Numako, C., $\mathrm{TiO}_{2}$-Derived Titanate Nanotubes by Hydrothermal Process with Acid Treatments and Their Microstructural Evaluation. ACS Appl. Mater. Interfaces 2010, 2, 2611-2616.

60. Poudel, B.; Wang, W. Z.; Dames, C.; Huang, J. Y.; Kunwar, S.; Wang, D. Z.; Banerjee, D.; Chen, G.; Ren, Z. F., Formation of Crystallized Titania Nanotubes and Their Transformation into Nanowires. Nanotechnology 2005, 16, 1935-1940.

61. Yoshida, R.; Suzuki, Y.; Yoshikawa, S., Effects of Synthetic Conditions and HeatTreatment on the Structure of Partially Ion-Exchanged Titanate Nanotubes. Mater. Chem. Phys. 2005, 91, 409-416.

62. Neelgund, G. M.; Shivashankar, S. A.; Chethana, B. K.; Sahoo, P. P.; Rao, K. J., Nanocrystalline $\mathrm{TiO}_{2}$ Preparation by Microwave Route and Nature of Anatase-Rutile Phase Transition in Nano $\mathrm{TiO}_{2}$. Bull. Mater. Sci. 2011, 34, 1163-1171.

63. Rodríguez-González, V.; Obregón-Alfaro, S.; Lozano-Sánchez, L. M.; Lee, S.-W., Rapid Microwave-Assisted Synthesis of One-Dimensional Silver-H2ti3o7 Nanotubes. J. Mol. Catal. A: Chem. 2012, 353-354, 163-170.

64. Wang, H.-W.; Kuo, C.-H.; Lin, H.-C.; Kuo, I. T.; Cheng, C.-F., Rapid Formation of Active Mesoporous $\mathrm{TiO}_{2}$ Photocatalysts Via Micelle in a Microwave Hydrothermal Process. J. Am. Ceram. Soc. 2006, 89, 3388-3392.

65. Sugimoto, T.; Zhou, X.; Muramatsu, A., Synthesis of Uniform Anatase $\mathrm{TiO}_{2}$ Nanoparticles by Gel-Sol Method: 3. Formation Process and Size Control. J. Colloid Interface Sci. 2003, 259, 43-52.

66. Green, D. W.; Perry, R. H., Perry's Chemical Engineers' Handbook, Eighth Edition. McGraw-Hill: New York, Chicago, San Francisco, Lisbon, London, Madrid, Mexico City, Milan, New Delhi, San Juan, Seoul, Singapore, Sydney, Toronto: 2008. 
67. Pan, X.; Zhao, Y.; Liu, S.; Korzeniewski, C. L.; Wang, S.; Fan, Z., Comparing Graphene- $\mathrm{TiO}_{2}$ Nanowire and Graphene- $\mathrm{TiO}_{2}$ Nanoparticle Composite Photocatalysts. ACS Appl. Mater. Interfaces 2012, 4, 3944-3950.

68. Yuan, Z.-Y.; Su, B.-L., Titanium Oxide Nanotubes, Nanofibers and Nanowires. Colloids and Surfaces A: Physicochemical and Engineering Aspects 2004, 241, 173-183.

69. Lan, Y.; Gao, X. P.; Zhu, H. Y.; Zheng, Z. F.; Yan, T. Y.; Wu, F.; Ringer, S. P.; Song, D. Y., Titanate Nanotubes and Nanorods Prepared from Rutile Powder. Adv. Funct. Mater. 2005, 15, 1310-1318.

70. Wu, D.; Liu, J.; Zhao, X.; Li, A.; Chen, Y.; Ming, N., Sequence of Events for the Formation of Titanate Nanotubes, Nanofibers, Nanowires, and Nanobelts. Chem. Mater. 2006, 18, 547-553.

71. Sallem, F.; Chassagnon, R.; Megriche, A.; El Maaoui, M.; Millot, N., Effect of Mechanical Stirring and Temperature on Dynamic Hydrothermal Synthesis of Titanate Nanotubes. J. Alloys Compd. 2017, 722, 785-796.

72. Liu, N.; Chen, X.; Zhang, J.; Schwank, J. W., A Review on $\mathrm{TiO}_{2}$-Based Nanotubes Synthesized Via Hydrothermal Method: Formation Mechanism, Structure Modification, and Photocatalytic Applications. Catal. Today 2014, 225, 34-51.

73. Wong, C. L.; Tan, Y. N.; Mohamed, A. R., A Review on the Formation of Titania Nanotube Photocatalysts by Hydrothermal Treatment. J. Environ. Manage. 2011, 92, 16691680.

74. Nakahira, A.; Kubo, T.; Numako, C., Formation Mechanism of $\mathrm{TiO}_{2}$-Derived Titanate Nanotubes Prepared by the Hydrothermal Process. Inorg. Chem. 2010, 49, 5845-5852.

75. Yao, B. D.; Chan, Y. F.; Zhang, X. Y.; Zhang, W. F.; Yang, Z. Y.; Wang, N., Formation Mechanism of $\mathrm{TiO}_{2}$ Nanotubes. Appl. Phys. Lett. 2003, 82, 281-283.

76. Chen, Q.; Du, G. H.; Zhang, S.; Peng, L.-M., The Structure of Trititanate Nanotubes. Acta Crystallogr., Sect. B: Struct. Sci. 2002, 58, 587-593.

77. Du, G. H.; Chen, Q.; Che, R. C.; Yuan, Z. Y.; Peng, L. M., Preparation and Structure Analysis of Titanium Oxide Nanotubes. Appl. Phys. Lett. 2001, 79, 3702-3704.

78. Lu, H.; Wang, Y.; Wang, Y.; Liang, W.; Yao, J., Adjusting Phase Transition of TitaniaBased Nanotubes Via Hydrothermal and Post Treatment. RSC Adv. 2015, 5, 89777-89782.

79. Tsai, C.-C.; Teng, H., Nanotube Formation from a Sodium Titanate Powder Via LowTemperature Acid Treatment. Langmuir 2008, 24, 3434-3438.

80. Tsai, C.-C.; Teng, H., Regulation of the Physical Characteristics of Titania Nanotube Aggregates Synthesized from Hydrothermal Treatment. Chem. Mater. 2004, 16, 4352-4358.

81. Qamar, M.; Yoon, C. R.; Oh, H. J.; Kim, D. H.; Jho, J. H.; Lee, K. S.; Lee, W. J.; Lee, H. G.; Kim, S. J., Effect of Post Treatments on the Structure and Thermal Stability of Titanate Nanotubes. Nanotechnology 2006, 17, 5922.

82. Huang, J.; Cao, Y.; Wang, M.; Huang, C.; Deng, Z.; Tong, H.; Liu, Z., Tailoring of Low-Dimensional Titanate Nanostructures. J. Phys. Chem. C 2010, 114, 14748-14754.

83. Suetake, J.; Nosaka, A. Y.; Hodouchi, K.; Matsubara, H.; Nosaka, Y., Characteristics of Titanate Nanotube and the States of the Confined Sodium Ions. J. Phys. Chem. C 2008, 112, 18474-18482.

84. Lee, C.-K.; Lin, K.-S.; Wu, C.-F.; Lyu, M.-D.; Lo, C.-C., Effects of Synthesis Temperature on the Microstructures and Basic Dyes Adsorption of Titanate Nanotubes. $J$. Hazard. Mater. 2008, 150, 494-503.

85. Gao, T.; Fjellvåg, H.; Norby, P., Crystal Structures of Titanate Nanotubes: A Raman Scattering Study. Inorg. Chem. 2009, 48, 1423-1432.

86. Khan, M. A.; Jung, H.-T.; Yang, O. B., Synthesis and Characterization of Ultrahigh Crystalline $\mathrm{TiO}_{2}$ Nanotubes. J. Phys. Chem. B 2006, 110, 6626-6630. 
87. Zhu, H. Y.; Lan, Y.; Gao, X. P.; Ringer, S. P.; Zheng, Z. F.; Song, D. Y.; Zhao, J. C., Phase Transition between Nanostructures of Titanate and Titanium Dioxides Via Simple WetChemical Reactions. J. Am. Chem. Soc. 2005, 127, 6730-6736.

88. Saponjic, Z. V.; Dimitrijevic, N. M.; Tiede, D. M.; Goshe, A. J.; Zuo, X.; Chen, L. X.; Barnard, A. S.; Zapol, P.; Curtiss, L.; Rajh, T., Shaping Nanometer-Scale Architecture through Surface Chemistry. Adv. Mater. 2005, 17, 965-971.

89. Dimitrijevic, N. M.; Saponjic, Z. V.; Bartels, D. M.; Thurnauer, M. C.; Tiede, D. M.; Rajh, T., Revealing the Nature of Trapping Sites in Nanocrystalline Titanium Dioxide by Selective Surface Modification. J. Phys. Chem. B 2003, 107, 7368-7375.

90. Erdem, B.; Hunsicker, R. A.; Simmons, G. W.; Sudol, E. D.; Dimonie, V. L.; El-Aasser, M. S., Xps and Ftir Surface Characterization of $\mathrm{TiO}_{2}$ Particles Used in Polymer Encapsulation. Langmuir 2001, 17, 2664-2669.

91. Lyons, A. S., Jr.; Tarr, M. A.; Prevost, R. M.; Gordon, S. W. In Modification of TiO 2 Nanoparticles for Increased Colloidal Stability under Biological Conditions for Eventual Use in Photodynamic Therapy, American Chemical Society: 2014; pp CHED-975.

92. Ma, Y.; Lin, Y.; Xiao, X.; Zhou, X.; Li, X., Sonication-Hydrothermal Combination Technique for the Synthesis of Titanate Nanotubes from Commercially Available Precursors. Mater. Res. Bull. 2006, 41, 237-243.

93. Morrison, R. A.; Rybak-Smith, M. J.; Townley, H. E.; Thompson, J. M.; Hill, M. A.; Thiebaut, B.; Townley, H. E., Efficacy of Radiosensitizing Doped Titania Nanoparticles under Hypoxia and Preparation of an Embolic Microparticle. Int. J. Nanomedicine 2017, 12, 38513863.

94. Mortazavi-Derazkola, S.; Salavati-Niasari, M.; Mazhari, M.-P.; Khojasteh, H.; Hamadanian, M.; Bagheri, S., Magnetically Separable $\mathrm{Fe}_{3} \mathrm{O}_{4} @ \mathrm{SiO}_{2} @ \mathrm{TiO}_{2} \mathrm{Nanostructures}$ Supported by Neodymium(III): Fabrication and Enhanced Photocatalytic Activity for Degradation of Organic Pollution. J. Mater. Sci.: Mater. Electron. 2017, 28, 14271-14281.

95. Nakagawa, K.; Yamaguchi, K.; Yamada, K.; Sotowa, K.-I.; Sugiyama, S.; Adachi, M., Synthesis and Characterization of Surface-Functionalized Layered Titanate Nanosheets Using Lamellar Self-Assembly as a Template. Eur. J. Inorg. Chem. 2012, n/a-n/a.

96. Ohya, T.; Nakayama, A.; Ban, T.; Ohya, Y.; Takahashi, Y., Synthesis and Characterization of Halogen-Free, Transparent, Aqueous Colloidal Titanate Solutions from Titanium Alkoxide. Chem. Mater. 2002, 14, 3082-3089.

97. Sugimoto, T. In Monodispersed Particles: Nucleation and Growth, CRC Press: 2016; pp 4776-4789.

98. Sugimoto, T.; Zhou, X.; Muramatsu, A., Synthesis of Uniform Anatase $\mathrm{TiO}_{2}$ Nanoparticles by Gelsol Method: 4. Shape Control. J. Colloid Interface Sci. 2003, 259, 53-61.

99. Zhou, X.; Peng, Z.; Wang, Z.; Wang, X., Effect of Trimethylamine on the Formation of Anatase Titania Nanoparticles by Gel-Sol Method. Colloid J. 2008, 70, 26-32.

100. Gao, Y.; Chen, G.; Oli, Y.; Zhang, Z.; Xue, Q., Study on Tribological Properties of Oleic Acid-Modified $\mathrm{TiO}_{2}$ Nanoparticle in Water. Wear 2002, 252, 454-458.

101. Thistlethwaite, P. J.; Hook, M. S., Diffuse Reflectance Fourier Transform Infrared Study of the Adsorption of Oleate/Oleic Acid onto Titania. Langmuir 2000, 16, 4993-4998.

102. Bingham, S.; Daoud, W. A., Recent Advances in Making Nano-Sized $\mathrm{TiO}_{2}$ VisibleLight Active through Rare-Earth Metal Doping. J. Mater. Chem. 2011, 21, 2041-2050.

103. Cozzoli, P. D.; Kornowski, A.; Weller, H., Low-Temperature Synthesis of Soluble and Processable Organic-Capped Anatase $\mathrm{TiO}_{2}$ Nanorods. J. Am. Chem. Soc. 2003, 125, 1453914548 .

104. Ge, M.; Cao, C.; Huang, J.; Li, S.; Chen, Z.; Zhang, K.-Q.; Al-Deyab, S. S.; Lai, Y., A Review of One-Dimensional $\mathrm{TiO}_{2}$ Nanostructured Materials for Environmental and Energy Applications. J. Mater. Chem. A 2016, 4, 6772-6801. 
105. Ming, H.; Kumar, P.; Yang, W.; Fu, Y.; Ming, J.; Kwak, W.-J.; Li, L.-J.; Sun, Y.-k.; Zheng, J., Green Strategy to Single Crystalline Anatase $\mathrm{TiO}_{2}$ Nanosheets with Dominant (001) Facets and Its Lithiation Study toward Sustainable Cobalt-Free Lithium Ion Full Battery. ACS Sustainable Chem. Eng. 2015, 3, 3086-3095.

106. Ong, W.-J.; Tan, L.-L.; Chai, S.-P.; Yong, S.-T.; Mohamed, A. R., Highly Reactive $\{001\}$ Facets of $\mathrm{TiO}_{2}$-Based Composites: Synthesis, Formation Mechanism and Characterization. Nanoscale 2014, 6, 1946-2008.

107. Ou, H.-H.; Lo, S.-L., Review of Titania Nanotubes Synthesized Via the Hydrothermal Treatment: Fabrication, Modification, and Application. Sep. Purif. Technol. 2007, 58, 179-191. 108. Sang, L.; Zhao, Y.; Burda, C., $\mathrm{TiO}_{2}$ Nanoparticles as Functional Building Blocks. Chem. Rev. 2014, 114, 9283-9318.

109. Menzel, R.; Duerrbeck, A.; Liberti, E.; Yau, H. C.; McComb, D.; Shaffer, M. S. P., Determining the Morphology and Photocatalytic Activity of Two-Dimensional Anatase Nanoplatelets Using Reagent Stoichiometry. Chem. Mater. 2013, 25, 2137-2145.

110. Li, X.-L.; Peng, Q.; Yi, J.-X.; Wang, X.; Li, Y., Near Monodisperse $\mathrm{TiO}_{2} \mathrm{Nanoparticles}^{2}$ and Nanorods. Chem. - Eur. J. 2006, 12, 2383-2391.

111. Dinh, C.-T.; Nguyen, T.-D.; Kleitz, F.; Do, T.-O., Shape-Controlled Synthesis of Highly Crystalline Titania Nanocrystals. ACS Nano 2009, 3, 3737-3743.

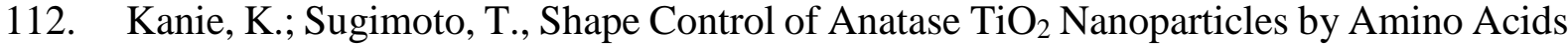
in a Gel-Sol System. Chem. Commun. 2004, 1584-1585.

113. Sugimoto, T.; Zhou, X.; Muramatsu, A., Synthesis of Uniform Anatase $\mathrm{TiO}_{2}$ Nanoparticles by Gel-Sol Method: 1. Solution Chemistry of $\mathrm{Ti}(\mathrm{OH})_{\mathrm{n}}{ }^{(4-\mathrm{n})+}$ Complexes. $J$. Colloid Interface Sci. 2002, 252, 339-346.

114. Sugimoto, T.; Zhou, X., Synthesis of Uniform Anatase $\mathrm{TiO}_{2}$ Nanoparticles by the GelSol Method 2. Adsorption of $\mathrm{OH}^{-}$Ions to $\mathrm{Ti}(\mathrm{OH})_{4} \mathrm{Gel}$ and $\mathrm{TiO}_{2}$ Particles. J. Colloid Interface Sci. 2002, 252, 347-353.

115. Sugimoto, T.; Okada, K.; Itoh, H., Synthetic of Uniform Spindle-Type Titania Particles by the Gel-Sol Method. J. Colloid Interface Sci. 1997, 193, 140-143.

116. Kessler, V. G.; Seisenbaeva, G. A.; Unell, M.; Haekansson, S., Chemically Triggered Biodelivery Using Metal-Organic Sol-Gel Synthesis. Angew. Chem., Int. Ed. 2008, 47, 85068509.

117. Rekha, S.; Martinez, A. I.; Safeera, T. A.; Anila, E. I., Enhanced Luminescence of Triethanolamine Capped Calcium Sulfide Nanoparticles Synthesized Using Wet Chemical Method. J. Lumin. 2017, 190, 94-99.

118. Jun, Y.-w.; Casula, M. F.; Sim, J.-H.; Kim, S. Y.; Cheon, J.; Alivisatos, A. P., Surfactant-Assisted Elimination of a High Energy Facet as a Means of Controlling the Shapes of $\mathrm{TiO}_{2}$ Nanocrystals. J. Am. Chem. Soc. 2003, 125, 15981-15985.

119. Barnard, A. S.; Curtiss, L. A., Prediction of $\mathrm{TiO}_{2}$ Nanoparticle Phase and Shape Transitions Controlled by Surface Chemistry. Nano Lett. 2005, 5, 1261-1266. 


\section{Caption to Scheme}

Scheme 1. Illustration of the reaction procedure to control the NNs aspect ratios: in red the parameters are varied in this study.

Caption to figures

Figure 1. a) and b) TEM images of scrolled nanosheets at two magnifications after the acid washing at $0.1 \mathrm{~N} \mathrm{HNO}_{3}$; c) HRTEM of the same SNSs showing the scrolled nature of the objects.

Figure 2. XRD Patterns of scrolled nanosheets after various washing procedures showing the importance of the $\mathrm{pH}$ on the resulting structure.

Figure 3. (a) TEM image and (b) XRD pattern of $\mathrm{TiO}_{2}$ nanoneedles (c) and (d) statistical distribution of nanoneedles length and width respectively. $\left(140{ }^{\circ} \mathrm{C}\right.$ for 72 hours at $\left.\mathrm{pH} 9.8\right)$.

Figure 4. (a and d) TEM images of fresh and 1-month old SNSs respectively; TEM images (b and e) and length distribution (c and f) of NNs obtained from fresh and 1-month old SNSs respectively ( $\mathrm{pH} 9.8$, hydrothermal treatment at $140{ }^{\circ} \mathrm{C}$ for 3 days).

Figure 5. a) Variation of the XRD pattern of the SNSs with time; b) variation of NNs length as a function of the age of SNSs ( $\mathrm{pH} 9.8$, hydrothermal treatment at $140{ }^{\circ} \mathrm{C}$ for 3 days).

Figure 6. Variation of the sizes of nanoneedles with the $\mathrm{pH}$. Each dot represents an average of 3 to 8 experiments: black dots for NNs length, blue ones for NNs width (each experiment being representative of a statistic on at least $300 \mathrm{NPs}$ ), bars represent the statistic errors on these experiments; inset: variation of the NNs aspect ratio with the $\mathrm{pH}$. In all cases, lines are guides for the eye. 
Figure 7. TEM images of NNs prepared with $500 \mu \mathrm{L}$ of a) triethanolamine (TEOA) and c) oleic acid (OA); b) and d) NNs length distribution for an initial $\mathrm{pH}$ of 9.8 .

Figure 8. Average NNs length without (as in Figure 6) and with structuring agents (TEOA or OA). The error bars are obtained by means of at least 3 experiments.

Figure 9. Variation of the NNs length, with the $\mathrm{pH}$ of the reaction medium in the absence (black dots) and in the presence of $500 \mu \mathrm{L}$ of both SAs (red dots). Results represent the averages of statistics of at least 300 NPs for each of the 3 sets of experiments per data point. Inset variation of the width and aspect ratio of the same objects obtained in the presence of the two SAs. Lines are guides for the eye.

Figure 10. Example of TEM images of $\mathrm{TiO}_{2}$ nanorods obtained at $\mathrm{pH} 4.4$ : a) in the absence of any capping agent; and b) in the presence of $500 \mu \mathrm{L}(3.76 \mathrm{mmol})$ of TEOA and $500 \mu \mathrm{L}(1.59$ mmol) OA starting with $2 \mathrm{~g}$ of SNSs (NRs length 34 (10), width: 15 (5) aspect ratio: 2 and c) starting with $0.7 \mathrm{~g}$ of SNSs (NRs length 73 (15), width: 21 (8) aspect ratio: 3).

Figure 11. TEM images of the different shapes of particles synthesized using $500 \mu \mathrm{L}$ of TEOA at pH 9.5 and respectively: a) $0 \mu \mathrm{L}$ of $\mathrm{OA}$, b) $500 \mu \mathrm{L}$ of OA, c) $800 \mu \mathrm{L}$ of OA; d) Variation of the NNs length with the amount of oleic acid at a fixed concentration of TEOA $(500 \mu \mathrm{L})$ at $\mathrm{pH}$ 9.5 on a set of a total of 3 experiments per point.

Figure 12. XRD pattern of NNs synthesized at initial $\mathrm{pH} 9.5$ with $(-)$ no structuring agent; $(-)$ $500 \mu \mathrm{L}$ of TEOA and $0 \mu \mathrm{L}$ of OA, (-) $500 \mu \mathrm{L}$ of TEOA and $500 \mu \mathrm{L}$ of OA.

Figure 13. HRTEM image and Fast Fourier Transform of a perfect NN. The inserted image in the particle is a simulated image along the [010] zone axis at Scherer defocus for a $5 \mathrm{~nm}$ thickness.

Figure 14. TEM image of a typical crystal in a NN form; inset: selected area electron diffraction pattern b) HRTEM image of the same NN showing a saw-tooth-like organization of the (101) planes on the external facet of the crystal. 
Figure 15. HRTEM image of a typical crystal in a nanorod shape.

For Table of Contents Only:

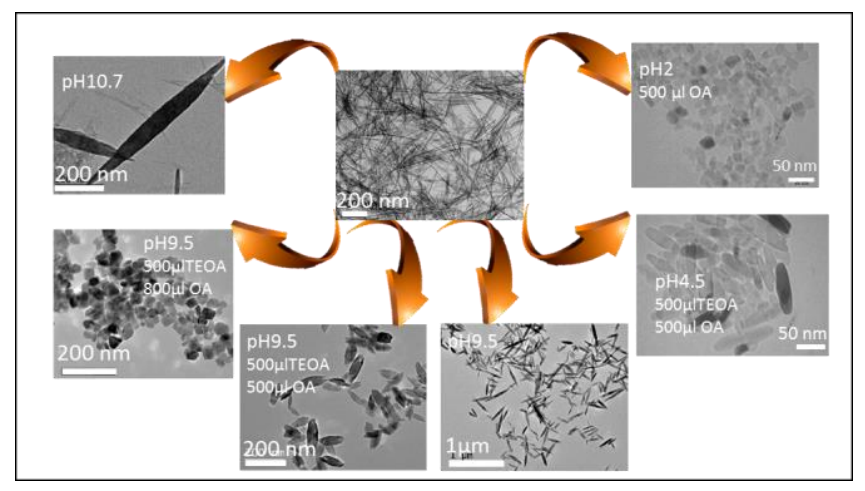

Table of Contents Synopsis: Smart selection of initial $\mathrm{pH}$ as well as Structuring Agents concentration and ratio provides a large choice of anatase anisotropic crystalline objects with aspects ratios from 1 to 10 under mild hydrothermal conditions. 